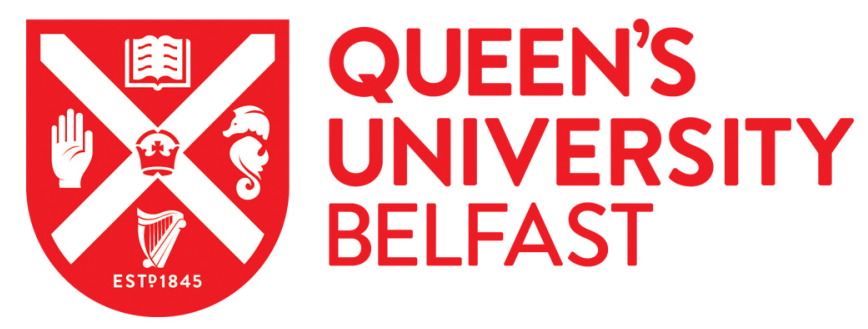

\title{
Electron-Impact Excitation of Ge III and Photoionisation of Ge II
}

Dunleavy, N. L., Ballance, C. P., Ramsbottom, C. A., \& Jeffery, C. S. (2021). Electron-Impact Excitation of Ge III and Photoionisation of Ge II. Monthly Notices of the Royal Astronomical Society, 506(4), 5398-5409. https://doi.org/10.1093/mnras/stab1974

\section{Published in:}

Monthly Notices of the Royal Astronomical Society

\section{Document Version:}

Publisher's PDF, also known as Version of record

\section{Queen's University Belfast - Research Portal:}

Link to publication record in Queen's University Belfast Research Portal

\section{Publisher rights}

Copyright 2021 The Author(s). Published by Oxford University Press on behalf of Royal Astronomical Society

This work is made available online in accordance with the publisher's policies. Please refer to any applicable terms of use of the publisher.

\section{General rights}

Copyright for the publications made accessible via the Queen's University Belfast Research Portal is retained by the author(s) and / or other copyright owners and it is a condition of accessing these publications that users recognise and abide by the legal requirements associated with these rights.

Take down policy

The Research Portal is Queen's institutional repository that provides access to Queen's research output. Every effort has been made to ensure that content in the Research Portal does not infringe any person's rights, or applicable UK laws. If you discover content in the Research Portal that you believe breaches copyright or violates any law, please contact openaccess@qub.ac.uk. 


\title{
Electron-impact excitation of Ge III and photoionization of Ge II
}

\author{
N. L. Dunleavy, ${ }^{1 \star}$ C. P. Ballance, ${ }^{1}$ C. A. Ramsbottom ${ }^{1}$ and C. S. Jeffery ${ }^{\circledR 2}$ \\ ${ }^{1}$ Centre for Theoretical Atomic, Molecular and Optical Physics, Queen's University Belfast, University Road, Belfast BT7 1NN, UK \\ ${ }^{2}$ Armagh Observatory and Planetarium, College Hill, Armagh BT61 9DG, UK
}

Accepted 2021 July 5. Received 2021 June 25; in original form 2021 April 30

\begin{abstract}
Energy levels, Einstein $A$-values, and oscillator strengths are calculated for doubly ionized germanium (Ge III). We have undertaken a study of the electron-impact excitation of Ge III and have also completed a study of the photoionization of Ge II. Ge III target structures were generated using the relativisticGRASP0 package. Several scattering models were investigated to assess the uncertainty quantification of our results. Initially, the lowest lying $64 \mathrm{jj}$ fine-structure levels were included in the close-coupling expansion resulting from 14 non-relativistic configurations. A second larger model was subsequently generated using the GASP package and incorporated the lowest $589 \mathrm{jj}$ fine-structure levels from 17 non-relativistic configurations. Both the DARC (Dirac atomic R-matrix code) and Breit-Pauli parallel suite of R-matrix collision codes were utilized in the scattering calculations to generate the collision strengths for incident electron energies between 0 and 5 Rydbergs and subsequently the Maxwellian-averaged effective collision strengths for temperatures in the range of 1000-200000 K. The photoionization calculations comprised of two studies, a DARC and a Breit-Pauli calculation incorporating the 250 lowest lying levels. Photoionization cross-sections for Ge II are presented in the range of 0-5 Ryds. Due to the lack of data available in the literature, the present radiative data and electron-impact/photoionization cross-sections are compared between the models presented in this paper. To assess their significance for astrophysics, the data are incorporated into the stellar atmosphere package STERNE. Test models for the heavy-metal subdwarf LS IV $-14^{\circ} 116$ are not affected by the new data, but models for cooler stars may be sensitive to them.
\end{abstract}

Key words: atomic data-atomic processes - opacity-scattering.

\section{INTRODUCTION}

Germanium has been detected within the Earth's crust at an abundance of approximately 1.6 ppm (Höll, Kling \& Schroll 2007). Its abundance in the Sun's atmosphere is roughly two parts per billion (Asplund et al. 2009). While it is unsurprising that germanium is not widely observed in astrophysical sources, trace amounts have been detected in the atmospheres of a few distant stars (Cowan 2003) and Jupiter (Kunde et al. 1982). Naslim et al. (2011) report the detection of doubly ionized yttrium $\mathrm{Y} 3$ and germanium Ge III and triply ionized zirconium Zr IV in the spectrum of the hot subdwarf LS IV $-14^{\circ} 116$. These represented the first detection of these ions in the optical spectrum of any star, and yielded measured abundances between 3 and 4.6 dex above the solar value and $>10 \mathrm{ppm}$ in absolute terms. These detections and overabundances were recently confirmed in LS IV $-14^{\circ} 116$, and also in the hot subdwarfs Feige 46 and PHL 417 (Dorsch et al. 2020; Østensen et al. 2020). Such abundances raise the question of their contribution to the opacity and structure of the stellar atmosphere, for which accurate atomic data are essential. In turn, such data are crucial to measurements of abundance from the absorption-line spectrum. Naslim et al. (2011) computed oscillator strengths for 11 observed zirconium, yttrium, and germanium lines using the configuration interaction (CI) code CIV3 (Hibbert 1975;

^E-mail: ndunleavy01@qub.ac.uk
Hibbert, Glass \& Fischer 1991). However, neither the overall Ge IV photoexcitation spectrum nor the photoionization of any germanium ions was extensively investigated.

Reliable experimental oscillator strength data sources for germanium species include Morton (2003) and the compilation of Fuhr \& Wiese (2005), but limited data are available for Ge III. Important examples of diagnostic strong lines for Ge III include the ${ }^{3} \mathrm{P}_{1}^{0}$ spin-forbidden line oscillator strength from the empirical predictions of Curtis (1992), and the resonance line $f$-value for the ${ }^{1} \mathrm{P}_{1}^{\mathrm{o}}$ level (Andersen et al. 1979). The latter authors used beamfoil spectroscopy to determine the resonance line experimentally. Other observed data can be seen in the work of Moore (1971) and Sugar \& Musgrove (1993). A theoretical study completed by Liu et al. (2006) carried out a large-scale ab initio calculation for the $4 \mathrm{~s}^{2} \mathrm{~S}_{0}-4 \mathrm{~s} 4 \mathrm{p}{ }^{1,3} \mathrm{P}_{0,1,2}$ transitions in the zinc-like sequence, using the multiconfiguration Dirac-Fock method.

Accurate data for photoionization are necessary to construct good models of opacity in stellar atmospheres. Electron-impact excitation cross-sections are also necessary in the case of collisional plasmas, in order to construct collisional-radiative models. Unfortunately, until recently there was a distinct lack of atomic data for observed lines of elements heavier than iron in dwarf and subdwarf stars, with the exception of tungsten and molybdenum due to their importance in fusion research. Data for ions of all elements up to calcium were computed for the Opacity Project (Cunto \& Mendoza 1992; Cunto et al. 1993; The Opacity Project Team 1995); data for a single ion 


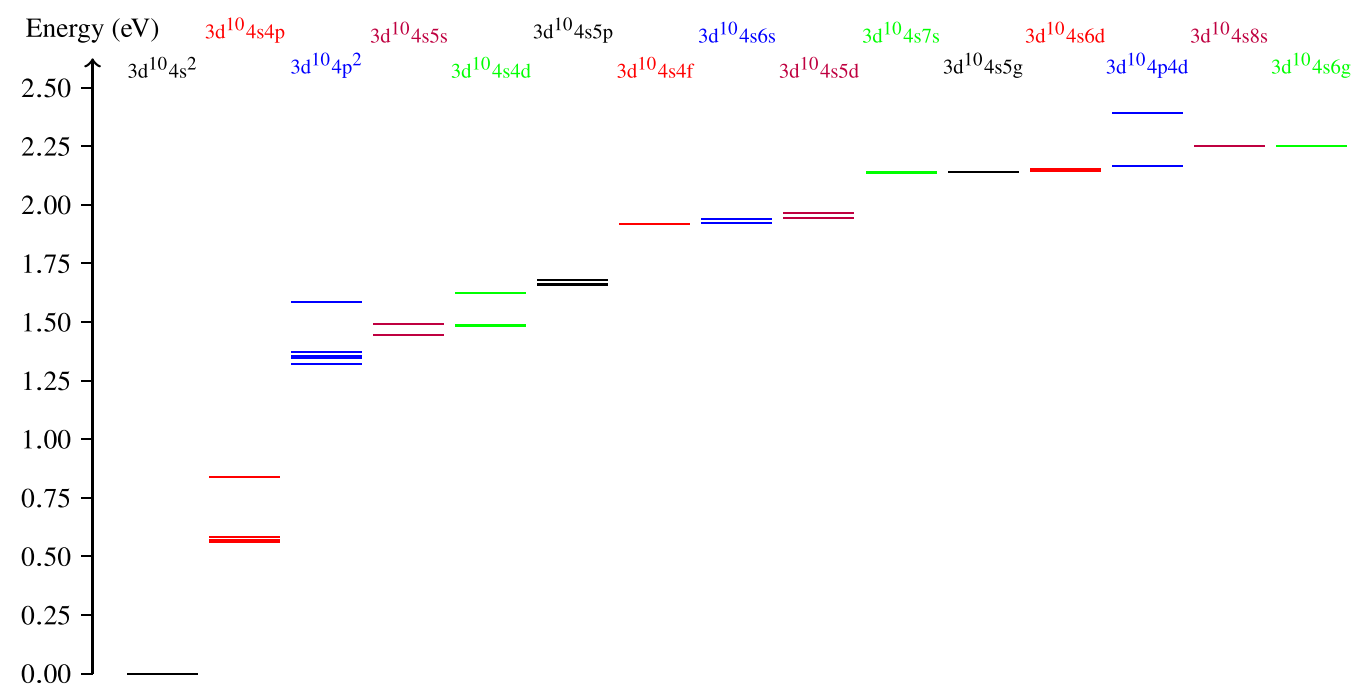

Figure 1. Energy level diagram of Ge III organized by electronic configuration. Each horizontal line designates a specific fine-structure level according to the NIST data base (Kramida et al. 2019).

stage of titanium, chromium, and nickel and five ions of iron were computed for the Iron Project (Hummer et al. 1993). OPEN-ADAS (Summers 2004) includes data for these heavy ions.

In recent years, iron peak elements have been studied by Smyth, Ballance \& Ramsbottom (2019), Smyth et al. (2018), and FernándezMenchero et al. (2019). Fernández-Menchero et al. (2020) have helped bridge the gap in accurate atomic data for trans-iron elements, specifically calculating photoionization cross-sections for $\mathrm{Sr}$, $\mathrm{Y}^{+}$, and $\mathrm{Zr}^{2+}$. Here, we turn attention to the trans-iron element germanium.

Calculating opacity is very important in understanding many highenergy processes. This is particularly evident in inertial confinement fusion schemes, where germanium is one of the elements used as a dopant in the ablator of the ignition target and is extensively studied by Benredjem et al. (2013) and Lee et al. (2020). In astrophysics, germanium is rarely found in high concentrations. One exception is found in the atmospheres of hot subdwarfs that provide conditions where trans-iron elements do become concentrated, as seen in heavymetal subdwarfs such as LS IV-14 ${ }^{\circ} 116$ (Naslim et al. 2011).

Section 1 evaluates and compares radiative models with the limited observed atomic data recorded in the literature, including the work of Sugar \& Musgrove (1993) found in the NIST data base (Kramida et al. 2019). Section 2 outlines two atomic structures for Ge III. The first model is constructed using the relativistic GRASP0 (general purpose relativistic atomic structure package) code, contains 14 configurations, and results in a 64 fine-structure level model. The structure contains shells up to the $6 \mathrm{~s}$ orbital, including the $4 \mathrm{f}$ subshell. The second model is created using the Breit-Pauli (BP) GASP (graphical autostructure package) code. This model comprises 17 configurations, producing 589 fine-structure levels and included orbitals up to the $5 \mathrm{~d}$ subshell. We present energy levels, transition probabilities, and oscillator strengths from both of these models, and where possible compared these radiative values with other theoretical and experimental data.

In Section 3, we present collision strengths, and the corresponding Maxwellian-averaged effective collision strengths, for electronimpact excitation of Ge III evaluated for both models, and show a test of convergence. Section 4 outlines the photoionization scattering calculation of Ge II and presents photoionization cross-sections from both ground and excited state levels. Section 5 investigates the consequences of the new atomic data for the structure and spectrum of a model atmosphere for the heavy-metal hot subdwarf LS IV-14 116 . In Section 6, we provide conclusion.

\section{ATOMIC STRUCTURE}

To determine an accurate structure of the Ge III target, we solve the relativistic Dirac equation. The Dirac equation is fully described in the work of Dirac \& Fowler (1928), and will only be briefly introduced here. The time-independent Dirac equation is defined as

$H_{\mathrm{DC}} \phi=E \phi$,

where $\phi$ is the Dirac orbital, $H_{\mathrm{DC}}$ is the Dirac-Coulomb Hamiltonian, and $E$ is the energy eigenvalue of the Hamiltonian. $H_{\mathrm{DC}}$ can be defined as

$H_{\mathrm{DC}}=c \boldsymbol{\alpha} \cdot \boldsymbol{p}+\left(\beta-\square_{4}\right) c^{2}+V(r)$,

where $c$ is the speed of light and $p$ is the momentum operator. $\mathbb{\square}_{4}$ is the $4 \times 4$ identity matrix, and the Dirac matrices $(\alpha$ and $\beta$ ) are also $4 \times 4$ matrices. Extending this Dirac Hamiltonian to consider electron-electron interactions produces a fully relativistic model of the $N+1$ electron system:

$H_{\mathrm{DC}}=\sum_{i=1}^{N+1}\left(c \boldsymbol{\alpha} \cdot \boldsymbol{p}_{i}+\left(\beta-\mathbb{\mathbb { V }}_{4}\right) c^{2}-\frac{Z}{r_{i}}\right)+\sum_{\substack{i, j \\ i>j}}^{N+1} \frac{1}{r_{i j}}$,

where $r_{i j}=\left|r_{j}-r_{i}\right|$.

Fig. 1 displays the energy level spectrum of Ge III taken from the NIST data base. In the present structure calculations, we utilize both the GASP (Badnell 2016) and the GRASP0 (Dyall et al. 1996) to create models of Ge III that were subsequently incorporated into scattering calculations using the Breit-Paul and DARC (Dirac atomic R-matrix code) codes (Ballance 2019), respectively. We calculate the energy levels of the target states of Ge III together with oscillator strengths and $A$-values for transitions between these states. By comparing with available NIST data, we can gauge the accuracy of the models produced, in a similar manner described for other targets - Fe II (Smyth et al. 2018), Mo I (Smyth et al. 2017), and Ni III and Ni IV (Fernández-Menchero et al. 2019). The GRASP0 structure model 
Table 1. Energy levels (Ryds) for the lowest lying 20 fine-structure states in Ge III obtained from both the GRASP and BP models. Comparisons are made with data available in NIST and the absolute errors for both models when compared to NIST.

\begin{tabular}{|c|c|c|c|c|c|c|c|c|}
\hline & Configuration & Parity & $J$ & $\begin{array}{l}\text { GRASP } \\
\text { Ryds }\end{array}$ & $\begin{array}{l}\text { BP } \\
\text { Ryds }\end{array}$ & $\begin{array}{l}\text { NIST } \\
\text { Ryds }\end{array}$ & $\begin{array}{l}\text { Absolute error } \\
\text { GRASP }\end{array}$ & $\begin{array}{c}\text { Absolute error } \\
\text { BP }\end{array}$ \\
\hline 1 & $3 d^{10} 4 s^{2}\left({ }^{1} S\right)$ & Even & 0 & $0.00 \mathrm{E}+00$ & $0.00 \mathrm{E}+00$ & $0.00 \mathrm{E}+00$ & $0.00 \mathrm{E}+00$ & $0.00 \mathrm{E}+00$ \\
\hline 2 & $3 d^{10} 4 s 4 p\left({ }^{3} P^{o}\right)$ & Odd & 0 & $5.33 \mathrm{E}-01$ & $5.68 \mathrm{E}-01$ & $5.63 \mathrm{E}-01$ & $2.96 \mathrm{E}-02$ & $5.25 \mathrm{E}-03$ \\
\hline 3 & $3 d^{10} 4 s 4 p\left({ }^{3} P^{o}\right)$ & Odd & 1 & $5.40 \mathrm{E}-01$ & $5.76 \mathrm{E}-01$ & $5.70 \mathrm{E}-01$ & $2.97 \mathrm{E}-02$ & $5.97 \mathrm{E}-03$ \\
\hline 4 & $3 \mathrm{~d}^{10} 4 \mathrm{~s} 4 \mathrm{p}\left({ }^{3} \mathrm{P}^{\mathrm{o}}\right)$ & Odd & 2 & $5.54 \mathrm{E}-01$ & $5.92 \mathrm{E}-01$ & $5.85 \mathrm{E}-01$ & $3.04 \mathrm{E}-02$ & $7.30 \mathrm{E}-03$ \\
\hline 5 & $3 \mathrm{~d}^{10} 4 \mathrm{~s} 4 \mathrm{p}\left({ }^{1} \mathrm{P}^{\mathrm{o}}\right)$ & Odd & 1 & $9.10 \mathrm{E}-01$ & $9.35 \mathrm{E}-01$ & $8.37 \mathrm{E}-01$ & $7.29 \mathrm{E}-02$ & $9.82 \mathrm{E}-02$ \\
\hline 6 & $3 \mathrm{~d}^{10} 4 \mathrm{p}^{2}\left({ }^{1} \mathrm{D}\right)$ & Even & 2 & $1.27 \mathrm{E}+00$ & $1.28 \mathrm{E}+00$ & $1.32 \mathrm{E}+00$ & $5.22 \mathrm{E}-02$ & $4.22 \mathrm{E}-02$ \\
\hline 7 & $3 \mathrm{~d}^{10} 4 \mathrm{p}^{2}\left({ }^{3} \mathrm{P}\right)$ & Even & 0 & $1.31 \mathrm{E}+00$ & $1.33 \mathrm{E}+00$ & $1.35 \mathrm{E}+00$ & $4.03 \mathrm{E}-02$ & $1.39 \mathrm{E}-02$ \\
\hline 8 & $3 \mathrm{~d}^{10} 4 \mathrm{p}^{2}\left({ }^{3} \mathrm{P}\right)$ & Even & 1 & $1.31 \mathrm{E}+00$ & $1.34 \mathrm{E}+00$ & $1.35 \mathrm{E}+00$ & $4.11 \mathrm{E}-02$ & $1.22 \mathrm{E}-02$ \\
\hline 9 & $3 \mathrm{~d}^{10} 4 \mathrm{p}^{2}\left({ }^{3} \mathrm{P}\right)$ & Even & 2 & $1.33 \mathrm{E}+00$ & $1.36 \mathrm{E}+00$ & $1.37 \mathrm{E}+00$ & $4.23 \mathrm{E}-02$ & $1.02 \mathrm{E}-02$ \\
\hline 10 & $3 d^{10} 4 s 5 s\left({ }^{3} S\right)$ & Even & 1 & $1.39 \mathrm{E}+00$ & $1.40 \mathrm{E}+00$ & $1.44 \mathrm{E}+00$ & $5.44 \mathrm{E}-02$ & $4.93 \mathrm{E}-02$ \\
\hline 11 & $3 \mathrm{~d}^{10} 4 \mathrm{~s} 5 \mathrm{~s}\left({ }^{1} \mathrm{~S}\right)$ & Even & 0 & $1.53 \mathrm{E}+00$ & $1.47 \mathrm{E}+00$ & $1.49 \mathrm{E}+00$ & $4.25 \mathrm{E}-02$ & $2.27 \mathrm{E}-02$ \\
\hline 12 & $3 d^{10} 4 s 4 d\left({ }^{3} D\right)$ & Even & 1 & $1.53 \mathrm{E}+00$ & $1.44 \mathrm{E}+00$ & $1.48 \mathrm{E}+00$ & $4.93 \mathrm{E}-02$ & $4.22 \mathrm{E}-02$ \\
\hline 13 & $3 d^{10} 4 s 4 d\left({ }^{3} D\right)$ & Even & 2 & $1.53 \mathrm{E}+00$ & $1.44 \mathrm{E}+00$ & $1.48 \mathrm{E}+00$ & $4.94 \mathrm{E}-02$ & $4.22 \mathrm{E}-02$ \\
\hline 14 & $3 d^{10} 4 s 4 d\left({ }^{3} D\right)$ & Even & 3 & $1.58 \mathrm{E}+00$ & $1.44 \mathrm{E}+00$ & $1.49 \mathrm{E}+00$ & $9.19 \mathrm{E}-02$ & $4.23 \mathrm{E}-02$ \\
\hline 15 & $3 \mathrm{~d}^{10} 4 \mathrm{p}^{2}\left({ }^{1} \mathrm{~S}\right)$ & Even & 0 & $1.60 \mathrm{E}+00$ & $1.66 \mathrm{E}+00$ & $1.59 \mathrm{E}+00$ & $1.55 \mathrm{E}-02$ & $7.34 \mathrm{E}-02$ \\
\hline 16 & $3 d^{10} 4 s 5 p\left({ }^{3} P^{o}\right)$ & Odd & 0 & $1.60 \mathrm{E}+00$ & $1.60 \mathrm{E}+00$ & $1.66 \mathrm{E}+00$ & $5.34 \mathrm{E}-02$ & $5.25 \mathrm{E}-02$ \\
\hline 17 & $3 d^{10} 4 s 5 p\left({ }^{3} P^{o}\right)$ & Odd & 1 & $1.61 \mathrm{E}+00$ & $1.61 \mathrm{E}+00$ & $1.66 \mathrm{E}+00$ & $5.11 \mathrm{E}-02$ & $5.16 \mathrm{E}-02$ \\
\hline 18 & $3 \mathrm{~d}^{10} 4 \mathrm{~s} 5 \mathrm{p}\left({ }^{3} \mathrm{P}^{\mathrm{o}}\right)$ & Odd & 2 & $1.64 \mathrm{E}+00$ & $1.61 \mathrm{E}+00$ & $1.66 \mathrm{E}+00$ & $2.35 \mathrm{E}-02$ & $5.00 \mathrm{E}-02$ \\
\hline 19 & $3 \mathrm{~d}^{10} 4 \mathrm{~s} 5 \mathrm{p}\left({ }^{1} \mathrm{P}^{\mathrm{o}}\right)$ & Odd & 1 & $1.78 \mathrm{E}+00$ & $1.68 \mathrm{E}+00$ & $1.68 \mathrm{E}+00$ & $1.01 \mathrm{E}-01$ & $2.45 \mathrm{E}-03$ \\
\hline 20 & $3 d^{10} 4 s 4 d\left({ }^{1} D\right)$ & Even & 2 & $1.86 \mathrm{E}+00$ & $1.68 \mathrm{E}+00$ & $1.62 \mathrm{E}+00$ & $2.41 \mathrm{E}-01$ & $6.09 \mathrm{E}-02$ \\
\hline
\end{tabular}

comprised following 14 configurations:

$$
\begin{array}{lccc}
3 p^{6} 3 d^{10} 4 s^{2} & 3 p^{6} 3 d^{10} 5 s^{2} & 3 p^{6} 3 d^{10} 4 s 5 s & 3 p^{6} 3 d^{10} 4 p 5 s \\
3 p^{6} 3 d^{10} 4 p^{2} & 3 p^{6} 3 d^{10} 6 s^{2} & 3 p^{6} 3 d^{10} 4 s 5 p & 3 p^{6} 3 d^{10} 4 p 5 p \\
3 p^{6} 3 d^{10} 4 d^{2} & 3 p^{6} 3 d^{10} 4 s 4 p & 3 p^{6} 3 d^{10} 4 s 5 d & \\
3 p^{6} 3 d^{10} 5 f^{2} & 3 p^{6} 3 d^{10} 4 s 4 f & 3 p^{6} 3 d^{10} 4 s 6 s &
\end{array}
$$

resulting in a 64 fine level structure. The BP model comprised following 17 configurations:

$$
\begin{array}{llll}
3 p^{6} 3 d^{10} 4 s^{2} & 3 p^{6} 3 d^{10} 4 s 4 p & 3 p^{6} 3 d^{8} 4 s^{2} 4 d^{2} & 3 p^{6} 3 d^{8} 4 s^{2} 5 s^{2} \\
3 p^{6} 3 d^{10} 4 p^{2} & 3 p^{6} 3 d^{10} 4 s 5 s & 3 p^{6} 3 d^{9} 4 s^{2} 4 p & 3 p^{6} 3 d^{8} 4 s^{2} 5 p^{2} \\
3 p^{6} 3 d^{10} 4 d^{2} & 3 p^{6} 3 d^{10} 4 s 5 p & 3 p^{6} 3 d^{9} 4 s^{2} 4 d & \\
3 p^{6} 3 d^{10} 5 s^{2} & 3 p^{6} 3 d^{10} 4 s 4 d & 3 p^{6} 3 d^{9} 4 s^{2} 5 s & \\
3 p^{6} 3 d^{10} 5 p^{2} & 3 p^{6} 3 d^{8} 4 s^{2} 4 p^{2} & 3 p^{6} 3 d^{9} 4 s^{2} 5 p &
\end{array}
$$

resulting in 589 fine-structure levels.

\subsection{Accuracy of models}

In order to evaluate the accuracy and uncertainty of our models, it is important to compare our data with known reliable sources. An established method of testing the accuracy of atomic structural models is to compare the energy levels and oscillator strengths with existing literature values, such as the values found in NIST. Existing literature for Ge III is lacking in detail, particularly for energy levels and transition probabilities. Therefore, it was paramount to generate several differing structures to enable cross-comparisons to be generated between them.

Table 1 displays the energy levels in Rydbergs for the 20 lowest lying states of Ge III included in both the GRASP0 and BP models. Comparisons are made with the energy levels available from NIST. These 20 levels identified were the only possible comparisons that could be drawn between the two models as they represented the only values listed in NIST. An absolute error of on average 5.56E-02 was found between the GRASP0 model energies and the NIST values, indicating that this model provides a reasonable representation for the configuration states presented in Table 1. The average absolute error between the BP model energies and NIST values shows an even more reasonable agreement at $3.42 \mathrm{E}-02$. Both models display a good representation of the configuration states. However, to ensure accuracy, it is also important to use another method of comparison. Table 2 displays the $A$-values and $f$-values of both models to check the agreement for a selection of transitions.

The models agree quite well for most transitions, particularly for the $3 \mathrm{~d}^{10} 4 \mathrm{~s} 4 \mathrm{p}{ }^{3} \mathrm{P}_{1}^{\mathrm{o}}-3 \mathrm{~d}^{10} 4 \mathrm{p}^{2}{ }^{1} \mathrm{~S}_{0}$ transition where the absolute error between $f$-values is less than $1.00 \mathrm{E}-04$. NIST did not contain any data for the oscillator strengths or $A$-values of Ge III. However, there were a few publications that tabulated limited data on select lines of the target. The only reliable data were recorded by Morton (2000), and contained a single comparable $f$-value, for the $3 \mathrm{~d}^{10} 4 \mathrm{~s}^{2}{ }^{1} \mathrm{~S}_{0}$ $3 \mathrm{~d}^{10} 4 \mathrm{~s} 4 \mathrm{p}{ }^{1} \mathrm{P}_{1}^{\mathrm{o}}(108.85 \mathrm{~nm})$ transition of 1.779 . This single value registered an absolute error of $2.41 \mathrm{E}-01$ when compared with both models. Another source of useful results was from Cashman et al. (2017); however, they graded their comparable Ge III results quite lowly $(\mathrm{C}+$ and ungraded $)$, two of the lowest reliability grades available.

Due to the lack of existing data for Ge III, it was pertinent to use a different method to test the accuracy of our data. Chi \& Chou (2014) present both theoretical and experimental lines of $\mathrm{Zn}$ III and Ga III, the neighbouring ion stages of Ge III. By extrapolating the $f$-values presented therein, we were able to compare their theoretical predictions with our data; see Table 2 . The predicted values based on both the theoretical and experimental data show good agreement with both the GRASP and Briet-Pauli models, particularly with the strong $3 \mathrm{~d}^{10} 4 \mathrm{~s}^{2}{ }^{1} \mathrm{~S}_{0}-3 \mathrm{~d}^{10} 4 \mathrm{~s} 4 \mathrm{p}{ }^{1} \mathrm{P}_{1}^{\mathrm{o}}$ line, where the average absolute error between the predicted $f$-values and our own data was $1.15 \mathrm{E}-01$.

\section{ELECTRON-IMPACT EXCITATION}

The scattering calculations implement the R-matrix theory fully described by Burke (2011) and Descouvemont \& Baye (2010). This theory will only be briefly summarized here. The R-matrix method partitions configuration space into two separate regions, an internal region and an external region, separated at the R-matrix boundary $r=$ 
Table 2. Einstein A coefficients ( $A$-values, $\mathrm{s}^{-1}$ ) and absorption oscillator strengths ( $f$-values in the length gauge) from both the GRASP and BP models, compared with the predicted values extrapolated from neighbouring ion stages in the work of Chi \& Chou (2014). Chi \& Chou (2014) present both theoretical (Theo.) and experimental (Exp.) results for Zn III and Ga III.

\begin{tabular}{|c|c|c|c|c|c|c|c|}
\hline $\begin{array}{l}\text { Lower } \\
\text { Configuration }\end{array}$ & $\begin{array}{c}\text { Upper } \\
\text { Configuration }\end{array}$ & $\begin{array}{l}A \text {-value: } \\
\text { GRASP }\end{array}$ & $\begin{array}{c}f \text {-value: } \\
\text { GRASP }\end{array}$ & $\begin{array}{c}A \text {-value: } \\
\text { BP }\end{array}$ & $\begin{array}{c}f \text {-value: } \\
\text { BP }\end{array}$ & $\begin{array}{c}f \text {-value: } \\
\text { Theo. }\end{array}$ & $\begin{array}{c}f \text {-value: } \\
\text { Exp. }\end{array}$ \\
\hline $3 d^{10} 4 s^{2}\left({ }^{1} S_{0}\right)$ & $\begin{array}{l}3 \mathrm{~d}^{10} 4 \mathrm{~s} 4 \mathrm{p}\left({ }^{3} \mathrm{P}_{1}^{\mathrm{o}}\right) \\
3 \mathrm{~d}^{10} 4 \mathrm{~s} 4 \mathrm{p}\left({ }^{1} \mathrm{P}_{1}^{\mathrm{o}}\right) \\
3 \mathrm{~d}^{10} 4 \mathrm{~s} 5 \mathrm{p}\left({ }^{3} \mathrm{P}_{1}^{\mathrm{o}}\right) \\
3 \mathrm{~d}^{10} 4 \mathrm{~s} 5 \mathrm{p}\left({ }^{1} \mathrm{P}_{1}^{\mathrm{o}}\right)\end{array}$ & $\begin{array}{l}3.75 \mathrm{E}+05 \\
4.48 \mathrm{E}+09 \\
6.04 \mathrm{E}+05 \\
1.90 \mathrm{E}+07\end{array}$ & $\begin{array}{l}4.81 \mathrm{E}-04 \\
2.02 \mathrm{E}+00 \\
8.80 \mathrm{E}-05 \\
2.65 \mathrm{E}-03\end{array}$ & $\begin{array}{l}7.23 \mathrm{E}+05 \\
4.73 \mathrm{E}+09 \\
2.93 \mathrm{E}+06 \\
4.02 \mathrm{E}+07\end{array}$ & $\begin{array}{l}8.16 \mathrm{E}-04 \\
2.02 \mathrm{E}+00 \\
4.23 \mathrm{E}-04 \\
5.31 \mathrm{E}-03\end{array}$ & $\begin{array}{c}- \\
2.13 \mathrm{E}+00 \\
- \\
-\end{array}$ & $\begin{array}{c}- \\
2.12 \mathrm{E}+00 \\
- \\
-\end{array}$ \\
\hline $3 \mathrm{~d}^{10} 4 \mathrm{~s} 4 \mathrm{p}\left({ }^{3} \mathrm{P}_{0}^{\mathrm{o}}\right)$ & $\begin{array}{c}3 \mathrm{~d}^{10} 4 \mathrm{p}^{2}\left({ }^{3} \mathrm{P}_{1}\right) \\
3 \mathrm{~d}^{10} 4 \mathrm{~s} 5 \mathrm{~s}\left({ }^{3} \mathrm{~S}_{1}\right) \\
3 \mathrm{~d}^{10} 4 \mathrm{~s} 4 \mathrm{~d}\left({ }^{3} \mathrm{D}_{1}\right)\end{array}$ & $\begin{array}{l}1.22 \mathrm{E}+09 \\
2.39 \mathrm{E}+08 \\
3.47 \mathrm{E}+09\end{array}$ & $\begin{array}{l}7.47 \mathrm{E}-01 \\
1.21 \mathrm{E}-01 \\
1.30 \mathrm{E}+00\end{array}$ & $\begin{array}{l}1.06 \mathrm{E}+09 \\
3.33 \mathrm{E}+08 \\
2.28 \mathrm{E}+09\end{array}$ & $\begin{array}{l}6.57 \mathrm{E}-01 \\
1.81 \mathrm{E}-01 \\
1.11 \mathrm{E}+00\end{array}$ & $\begin{array}{c}- \\
1.89 \mathrm{E}-01 \\
1.29 \mathrm{E}+00\end{array}$ & $\begin{array}{c}- \\
2.04 \mathrm{E}-01 \\
1.36 \mathrm{E}+00\end{array}$ \\
\hline $3 \mathrm{~d}^{10} 4 \mathrm{~s} 4 \mathrm{p}\left({ }^{3} \mathrm{P}_{1}^{\mathrm{o}}\right)$ & $\begin{array}{c}3 \mathrm{~d}^{10} 4 \mathrm{p}^{2}\left({ }^{1} \mathrm{D}_{2}\right) \\
3 \mathrm{~d}^{10} 4 \mathrm{p}^{2}\left({ }^{3} \mathrm{P}_{0}\right) \\
3 \mathrm{~d}^{10} 4 \mathrm{p}^{2}\left({ }^{3} \mathrm{P}_{1}\right) \\
3 \mathrm{~d}^{10} 4 \mathrm{p}^{2}\left({ }^{3} \mathrm{P}_{2}\right) \\
3 \mathrm{~d}^{10} 4 \mathrm{~s} 5 \mathrm{~s}\left({ }^{3} \mathrm{~S}_{1}\right) \\
3 \mathrm{~d}^{10} 4 \mathrm{~s} 5 \mathrm{~s}\left({ }^{1} \mathrm{~S}_{0}\right) \\
3 \mathrm{~d}^{10} 4 \mathrm{~s} 4 \mathrm{~d}\left({ }^{3} \mathrm{D}_{1}\right) \\
3 \mathrm{~d}^{10} 4 \mathrm{~s} 4 \mathrm{~d}\left({ }^{3} \mathrm{D}_{2}\right) \\
3 \mathrm{~d}^{10} 4 \mathrm{p}^{2}\left({ }^{1} \mathrm{~S}_{0}\right)\end{array}$ & $\begin{array}{l}1.88 \mathrm{E}+07 \\
3.39 \mathrm{E}+09 \\
8.92 \mathrm{E}+08 \\
9.12 \mathrm{E}+08 \\
7.44 \mathrm{E}+08 \\
9.00 \mathrm{E}+05 \\
2.58 \mathrm{E}+09 \\
4.62 \mathrm{E}+09 \\
1.00 \mathrm{E}+07\end{array}$ & $\begin{array}{l}2.20 \mathrm{E}-02 \\
7.20 \mathrm{E}-01 \\
5.57 \mathrm{E}-01 \\
9.13 \mathrm{E}-01 \\
3.84 \mathrm{E}-01 \\
1.37 \mathrm{E}-04 \\
9.78 \mathrm{E}-01 \\
2.92 \mathrm{E}+00 \\
1.16 \mathrm{E}-03\end{array}$ & $\begin{array}{l}8.58 \mathrm{E}+06 \\
2.95 \mathrm{E}+09 \\
7.67 \mathrm{E}+08 \\
8.14 \mathrm{E}+08 \\
9.96 \mathrm{E}+08 \\
3.32 \mathrm{E}+06 \\
1.68 \mathrm{E}+09 \\
3.03 \mathrm{E}+09 \\
1.09 \mathrm{E}+07\end{array}$ & $\begin{array}{l}1.08 \mathrm{E}-02 \\
6.41 \mathrm{E}-01 \\
4.87 \mathrm{E}-01 \\
8.23 \mathrm{E}-01 \\
5.53 \mathrm{E}-01 \\
5.19 \mathrm{E}-04 \\
8.36 \mathrm{E}-01 \\
2.51 \mathrm{E}+00 \\
1.16 \mathrm{E}-03\end{array}$ & $\begin{array}{c}- \\
- \\
- \\
- \\
3.64 \mathrm{E}-01 \\
- \\
8.31 \mathrm{E}-01 \\
- \\
-\end{array}$ & $\begin{array}{c}- \\
- \\
- \\
- \\
3.50 \mathrm{E}-01 \\
- \\
8.80 \mathrm{E}-01 \\
- \\
-\end{array}$ \\
\hline $3 \mathrm{~d}^{10} 4 \mathrm{~s} 4 \mathrm{p}\left({ }^{3} \mathrm{P}_{2}^{\mathrm{o}}\right)$ & $\begin{array}{c}3 \mathrm{~d}^{10} 4 \mathrm{p}^{2}\left({ }^{1} \mathrm{D}_{2}\right) \\
3 \mathrm{~d}^{10} 4 \mathrm{p}^{2}\left({ }^{3} \mathrm{P}_{1}\right) \\
3 \mathrm{~d}^{10} 4 \mathrm{p}^{2}\left({ }^{3} \mathrm{P}_{2}\right) \\
3 \mathrm{~d}^{10} 4 \mathrm{~s} 5 \mathrm{~s}\left({ }^{3} \mathrm{~S}_{1}\right) \\
3 \mathrm{~d}^{10} 4 \mathrm{~s} 4 \mathrm{~d}\left({ }^{3} \mathrm{D}_{1}\right) \\
3 \mathrm{~d}^{10} 4 \mathrm{~s} 4 \mathrm{~d}\left({ }^{3} \mathrm{D}_{2}\right) \\
3 \mathrm{~d}^{10} 4 \mathrm{~s} 4 \mathrm{~d}\left({ }^{3} \mathrm{D}_{3}\right)\end{array}$ & $\begin{array}{l}3.89 \mathrm{E}+07 \\
1.34 \mathrm{E}+09 \\
2.57 \mathrm{E}+09 \\
1.33 \mathrm{E}+09 \\
1.69 \mathrm{E}+08 \\
1.52 \mathrm{E}+09 \\
6.02 \mathrm{E}+09\end{array}$ & $\begin{array}{l}4.74 \mathrm{E}-02 \\
8.68 \mathrm{E}-01 \\
2.67 \mathrm{E}+00 \\
7.11 \mathrm{E}-01 \\
6.61 \mathrm{E}-02 \\
9.86 \mathrm{E}-01 \\
5.47 \mathrm{E}+00\end{array}$ & $\begin{array}{l}2.18 \mathrm{E}+07 \\
1.20 \mathrm{E}+09 \\
2.28 \mathrm{E}+09 \\
1.66 \mathrm{E}+09 \\
1.08 \mathrm{E}+08 \\
9.77 \mathrm{E}+08 \\
3.91 \mathrm{E}+09\end{array}$ & $\begin{array}{l}2.87 \mathrm{E}-02 \\
7.95 \mathrm{E}-01 \\
2.41 \mathrm{E}+00 \\
9.57 \mathrm{E}-01 \\
5.59 \mathrm{E}-02 \\
8.41 \mathrm{E}-01 \\
4.71 \mathrm{E}+00\end{array}$ & $\begin{array}{c}- \\
1.70 \mathrm{E}-01 \\
- \\
- \\
- \\
8.90 \mathrm{E}-01 \\
-\end{array}$ & $\begin{array}{c}- \\
1.65 \mathrm{E}-01 \\
- \\
- \\
- \\
9.44 \mathrm{E}-01 \\
-\end{array}$ \\
\hline $3 \mathrm{~d}^{10} 4 \mathrm{~s} 4 \mathrm{p}\left({ }^{1} \mathrm{P}_{1}^{\mathrm{o}}\right)$ & $\begin{array}{c}3 \mathrm{~d}^{10} 4 \mathrm{p}^{2}\left({ }^{3} \mathrm{P}_{0}\right) \\
3 \mathrm{~d}^{10} 4 \mathrm{p}^{2}\left({ }^{3} \mathrm{P}_{1}\right) \\
3 \mathrm{~d}^{10} 4 \mathrm{p}^{2}\left({ }^{3} \mathrm{P}_{2}\right) \\
3 \mathrm{~d}^{10} 4 \mathrm{~s} 5 \mathrm{~s}\left({ }^{3} \mathrm{~S}_{1}\right) \\
3 \mathrm{~d}^{10} 4 \mathrm{~s} 5 \mathrm{~s}\left({ }^{1} \mathrm{~S}_{0}\right) \\
3 \mathrm{~d}^{10} 4 \mathrm{~s} 4 \mathrm{~d}\left({ }^{3} \mathrm{D}_{1}\right) \\
3 \mathrm{~d}^{10} 4 \mathrm{~s} 4 \mathrm{~d}\left({ }^{3} \mathrm{D}_{2}\right) \\
3 \mathrm{~d}^{10} 4 \mathrm{p}^{2}\left({ }^{1} \mathrm{~S}_{3}\right)\end{array}$ & $\begin{array}{l}3.67 \mathrm{E}+06 \\
6.77 \mathrm{E}+04 \\
8.81 \mathrm{E}+05 \\
2.51 \mathrm{E}+05 \\
1.45 \mathrm{E}+09 \\
5.03 \mathrm{E}+05 \\
7.51 \mathrm{E}+05 \\
3.21 \mathrm{E}+09\end{array}$ & $\begin{array}{l}2.93 \mathrm{E}-03 \\
1.56 \mathrm{E}-04 \\
3.14 \mathrm{E}-03 \\
4.07 \mathrm{E}-04 \\
6.29 \mathrm{E}-01 \\
4.85 \mathrm{E}-04 \\
1.20 \mathrm{E}-03 \\
8.98 \mathrm{E}-01\end{array}$ & $\begin{array}{l}5.39 \mathrm{E}+06 \\
8.65 \mathrm{E}+04 \\
2.51 \mathrm{E}+05 \\
5.28 \mathrm{E}+05 \\
2.17 \mathrm{E}+09 \\
4.91 \mathrm{E}+05 \\
7.03 \mathrm{E}+05 \\
2.21 \mathrm{E}+09\end{array}$ & $\begin{array}{l}4.27 \mathrm{E}-03 \\
1.95 \mathrm{E}-04 \\
8.66 \mathrm{E}-04 \\
9.30 \mathrm{E}-04 \\
9.53 \mathrm{E}-01 \\
7.16 \mathrm{E}-04 \\
1.70 \mathrm{E}-03 \\
5.23 \mathrm{E}-01\end{array}$ & $\begin{array}{l}- \\
- \\
- \\
- \\
- \\
- \\
- \\
-\end{array}$ & $\begin{array}{l}- \\
- \\
- \\
- \\
- \\
- \\
- \\
-\end{array}$ \\
\hline $3 d^{10} 4 p^{2}\left({ }^{1} D_{2}\right)$ & $\begin{array}{l}3 d^{10} 4 s 5 p\left({ }^{3} P_{1}^{o}\right) \\
3 d^{10} 4 s 5 p\left({ }^{3} P_{2}^{o}\right) \\
3 d^{10} 4 s 5 p\left({ }^{1} P_{1}^{o}\right)\end{array}$ & $\begin{array}{l}4.16 \mathrm{E}+05 \\
7.92 \mathrm{E}+03 \\
1.22 \mathrm{E}+08\end{array}$ & $\begin{array}{l}1.39 \mathrm{E}-03 \\
4.30 \mathrm{E}-05 \\
3.33 \mathrm{E}-01\end{array}$ & $\begin{array}{l}1.33 \mathrm{E}+06 \\
5.23 \mathrm{E}+03 \\
4.59 \mathrm{E}+08\end{array}$ & $\begin{array}{l}4.60 \mathrm{E}-03 \\
2.92 \mathrm{E}-05 \\
1.06 \mathrm{E}+00\end{array}$ & $\begin{array}{l}- \\
- \\
-\end{array}$ & $\begin{array}{l}- \\
- \\
-\end{array}$ \\
\hline
\end{tabular}

a. This boundary is chosen to enclose the most diffuse orbital. The inner region solves the full many-body problem and the outer region solves the two-body problem where the outgoing electron moves in a multipole expansion of the target. We define the R-matrix as the following:

$R_{i j}=\frac{1}{2 a} \sum_{k} \frac{w_{i k}(a) w_{j k}(a)}{E_{k}^{N+1}-E}$,

where $E_{k}^{N+1}$ are the eigenenergies of the $N+1$ Hamiltonian, $E$ is the energy of the incoming electron, and $w_{i k}$ are the surface amplitudes. The R-matrix defined here acts as an interface between the two regions. In the external region, defining the energy of the incoming electron to be $k_{i}^{2}$ and taking a Maxwellian convolution of the crosssections $\sigma_{i \rightarrow j}$ allow the collision strengths between an initial state $i$ and a final state $j$ to be obtained as follows:

$\Omega_{i \rightarrow j}=\frac{g_{i} k_{i}^{2}}{\pi a_{0}^{2}} \sigma_{i \rightarrow j}$,

where the initial state function has a statistical weight of $g_{i}$ and $a_{0}$ is the Bohr radius. These collision strengths are used to generate
Maxwellian-averaged effective collision strengths $(\gamma)$ :

$\gamma_{i j}\left(T_{e}\right)=\int_{0}^{\infty} \Omega_{i \rightarrow j} \exp \left(-\frac{\epsilon_{j}}{k T_{e}}\right) d\left(\frac{\epsilon_{j}}{k T_{e}}\right)$,

where the scattered electron has energy $\epsilon_{j}$. The temperature of the electron is $T_{e}$ in Kelvin, and $k$ is the Boltzmann's constant.

\subsection{Calculation}

Two calculations were completed for the electron-impact excitation of Ge III. As mentioned in Section 1, the first was a fully relativistic DARC evaluation incorporating the $64 \mathrm{jj}$-level GRASP0 model (model 1). Due to the compact size of the diagonalization of matrices, all 64 levels were retained in the wavefunction expansion for this calculation. The second evaluation utilized the BP suite of computer packages incorporating the more sophisticated $589 \mathrm{jj}$-level structure produced using autostructure (model 2). Again, all 589 levels were retained in the wavefunction expansion for this second calculation. Both investigations were completed for a total of $60 \mathrm{~J} \pi$ partial waves from $2 J=1$ up to and including $2 J=59$. For higher partial waves $(2 J>59)$, a top-up procedure (described by Burgess 1974) was used 

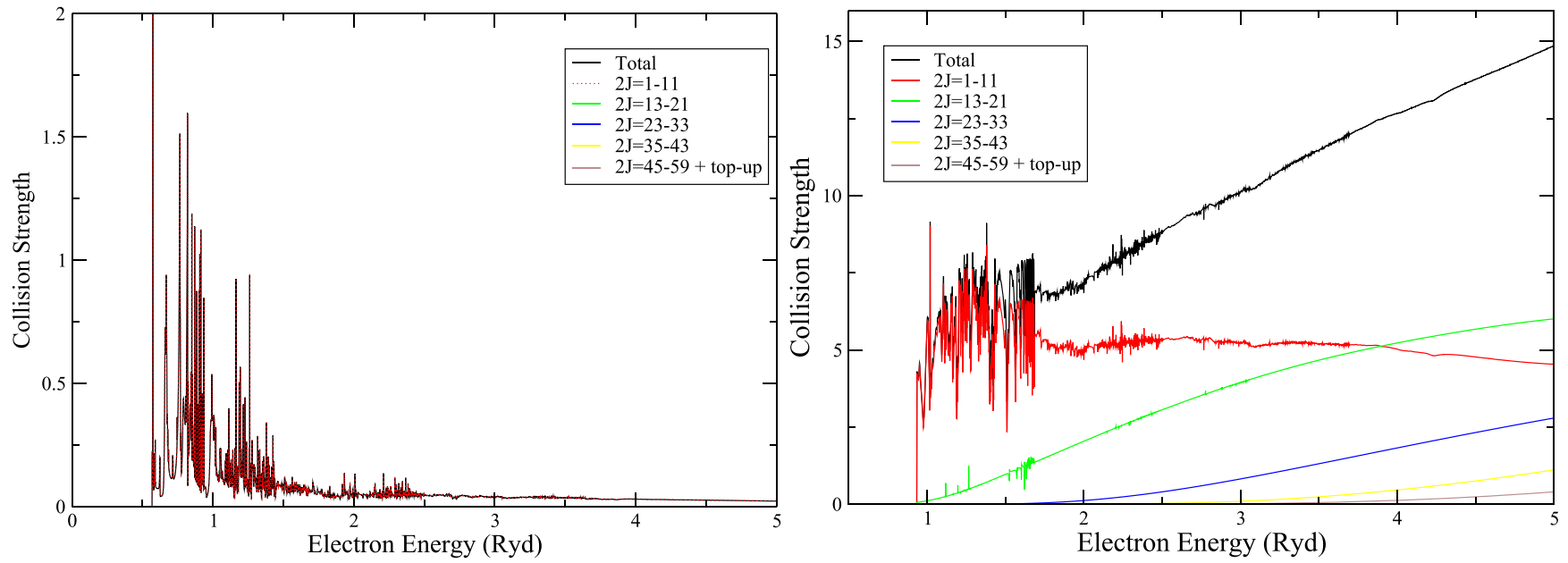

Figure 2. $\mathrm{J} \pi$ partial wave contributions to the collision strengths for the $3 \mathrm{~d}^{10} 4 \mathrm{~s}^{2}{ }^{1} \mathrm{~S}_{0}-3 \mathrm{~d}^{10} 4 \mathrm{p}^{2}{ }^{1} \mathrm{D}_{2}$ (1-6) (left-hand panel) and $3 \mathrm{~d}^{10} 4 \mathrm{~s}^{2}{ }^{1} \mathrm{~S}_{0}-3 \mathrm{~d}^{10} 4 \mathrm{~s} 4 \mathrm{p}^{3} \mathrm{P}_{0}^{o}(1-2)$ (right-hand panel) transitions, respectively.

to estimate the contribution of these partial waves to the collision strengths for all transitions.

\subsection{Convergence and accuracy}

Evaluating the accuracy of our scattering calculation is difficult due to the lack of comprehensive data sets within the literature. However, it is possible to carefully analyse aspects of the models such as the the convergence effects of including successively higher $J \pi$ partial waves on the collision strengths for the BP calculation. However, perhaps the most impartial comparison of results between the BP and DARC calculations is the greatest indication of uncertainty, as the final collision strengths are dependent on different atomic structures and different suites of scattering codes.

Fig. 2 presents the results from the BP calculation, emphasizing how the inclusion of successively higher partial waves affects the collision strengths of the $3 \mathrm{~d}^{10} 4 \mathrm{~s}^{2}{ }^{1} \mathrm{~S}_{0}-3 \mathrm{~d}^{10} 4 \mathrm{p}^{2}{ }^{1} \mathrm{D}_{2}$ (1-6) and $3 d^{10} 4 s^{2}{ }^{1} S_{0}-3 d^{10} 4 s 4 p{ }^{3} P_{0}^{o}(1-2)$ transitions, respectively. For the forbidden transition (1-6), the lowest $\mathrm{J} \pi$ partial waves $(2 J=1-11)$ provide the largest contributions, and the higher partial waves provide negligible contributions. Unsurprisingly, for the dipole transition (1-2) the largest contributions are also provided by the lowest $\mathrm{J} \pi$ partial waves. As the value of $J$ increases, the contribution decreases but the contributions from the higher partial waves can no longer be ignored, particularly at larger electron energies. By considering the contributions from the final 15 partial waves $(2 J=45-59)$, it can be seen that the contribution is reduced to a negligible amount. Partial waves from $2 J>59$ are expected to provide even smaller contributions and hence we may deduce that in terms of the number of partial waves included we have achieved sufficient convergence within the computed collision strengths.

\subsection{Results}

The collision strengths between two states (defined by equation 5) graphically show that strong auto-ionizing resonances can cause the $\Omega_{i j}$ to vary widely from the non-resonant background. These strong resonances often occur at energies below the ionization threshold. Due to the sensitivity of $\Omega_{i j}$, many astrophysicists prefer to use Maxwellian-averaged effective collision strengths, $\gamma_{i j}$, defined in equation (6), for a range of electron temperatures of importance. We present in Figs. 3 and 4, the collision strengths and corresponding Maxwellian-averaged effective collision strengths for several transitions. The collision strengths are presented for electron energies in the range of 0-5 Ryds, and the effective collision strengths are presented for astrophysically important temperatures in the range of 1000-2000 $000 \mathrm{~K}$.

In Fig. 3, we present the collision strength as a function of electron energy in Ryds relative to the initial state and the corresponding effective collision strength as a function of electron temperature in Kelvin, for the forbidden transitions between the $3 \mathrm{~d}^{10} 4 \mathrm{~s} 4 \mathrm{p}{ }^{3} \mathrm{P}_{0}^{\mathrm{o}}$ and $3 \mathrm{~d}^{10} 4 \mathrm{~s} 4 \mathrm{p}{ }^{3} \mathrm{P}_{1}^{\mathrm{o}}$ states $(2-3)$, and the $3 \mathrm{~d}^{10} 4 \mathrm{~s} 4 \mathrm{p}{ }^{3} \mathrm{P}_{2}^{\mathrm{o}}$ and $3 \mathrm{~d}^{10} 4 \mathrm{~s} 4 \mathrm{p}{ }^{1} \mathrm{P}_{1}^{\mathrm{o}}$ states (4-5), respectively. For comparison purposes, both the BP and DARC results are presented. For the two transitions, the collision strengths exhibit large resonance features at low-lying energies reducing to a smooth background cross-section after the ionization limit of approximately 2.5 Ryds. Slight differences are evident in the positioning and magnitudes of the low-lying resonances predicted by the two calculations. This is not unexpected due to the differing CI terms included in the wavefunction expansion of the target ion in the two models. These differences are highlighted by the effective collision strengths for both transitions where we see some discrepancies at the lowest temperatures considered. Excellent agreement is evident; however, for all temperatures above approximately $10^{4} \mathrm{~K}$.

Fig. 4 presents the collision strengths and effective collision strengths for the strong dipole allowed $3 \mathrm{~d}^{10} 4 \mathrm{~s}^{2} \mathrm{~S}_{0}$ to $3 \mathrm{~d}^{10} 4 \mathrm{~s} 4 \mathrm{p}$ ${ }^{1} \mathrm{P}_{1}^{\mathrm{o}}(1-5)$ and $3 \mathrm{~d}^{10} 4 \mathrm{~s} 4 \mathrm{p}{ }^{1} \mathrm{P}_{1}^{\mathrm{o}}$ to $3 \mathrm{~d}^{10} 4 \mathrm{p}^{2}{ }^{1} \mathrm{~S}_{0}$ (5-15) transitions, respectively. For these dipole allowed transitions, good agreement is evident when the DARC and BP calculations are compared. It should be noted; however, that the DARC cross-sections appear to be slightly stronger than the BP. This can be attributed to the fact that as the BP calculation contains substantially more CI than the DARC calculation there is stronger mixing between the levels, an effect that can lead to flux being diverted away from the strong low-lying transitions and transferred to the higher lying transitions. The effect of this is mirrored in the effective collision strength plots, where we see good agreement at all temperatures, the DARC calculation consistently producing the stronger effective collision strengths for the dipole allowed transitions presented in Fig. 4. 

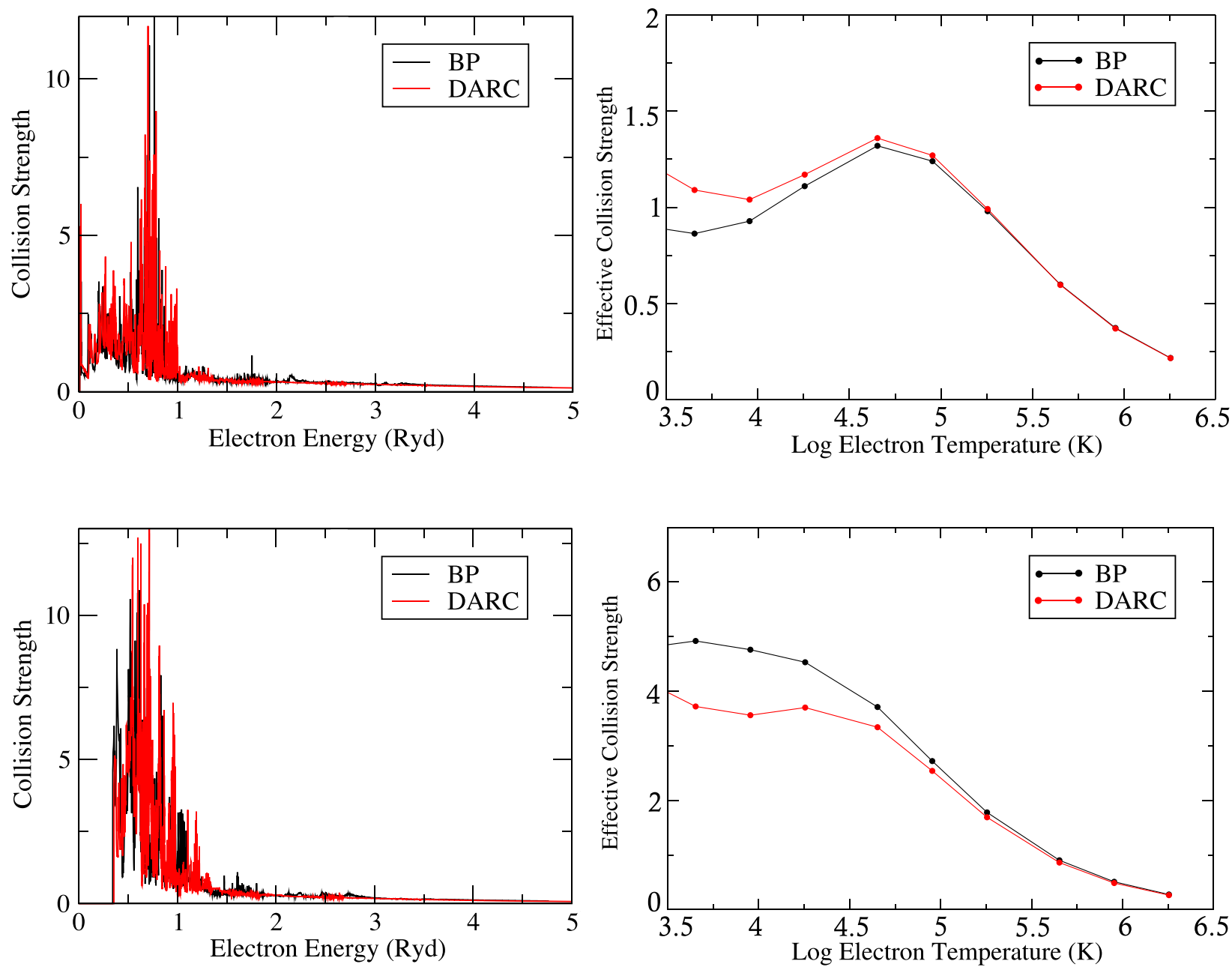

Figure 3. Collision strengths and effective collision strengths for the $3 \mathrm{~d}^{10} 4 \mathrm{~s} 4 \mathrm{p}^{3} \mathrm{P}_{0}^{\mathrm{o}}-3 \mathrm{~d}^{10} 4 \mathrm{~s} 4 \mathrm{p}{ }^{3} \mathrm{P}_{1}^{\mathrm{o}}$ (2-3) and $3 \mathrm{~d}^{10} 4 \mathrm{~s} 4 \mathrm{p}^{3} \mathrm{P}_{2}^{\mathrm{o}}-3 \mathrm{~d}^{10} 4 \mathrm{~s} 4 \mathrm{p}{ }^{1} \mathrm{P}_{1}^{\mathrm{o}}(4-5)$ forbidden transitions, respectively, from top to bottom. Presented are both the BP and DARC calculations.

\section{PHOTOIONIZATION}

In R-matrix theory, the photoionization cross-section is defined through the dipole matrix elements between the initial state $\psi_{0}$ and the R-matrix basis states $\psi_{k}$ provided that all radial orbitals of the initial state are well confined to the inner region. For a photon energy $\omega$, in Rydbergs, the total photoionization cross-section is defined as

$\sigma(\omega)=\frac{8}{3} \pi^{2} \alpha \omega^{ \pm 1} \frac{1}{\left(2 L_{0}+1\right)} \sum_{j}\left|\left(\psi_{j}^{-}\|D\| \psi_{0}\right)\right|^{2}$,

in $a_{0}^{2} . L_{0}$ is the orbital angular momentum of the initial state, $\alpha$ is the fine-structure constant equal to approximately $1 / 137$, and $D$ is the electric dipole operator. $\omega^{+1}$ and $\omega^{-1}$ correspond to the length and velocity forms, respectively, the index $j$ runs across the open channels, and $\psi_{j}^{-}$corresponds to asymptotic conditions with a plane wave in the direction of the ejected electron momentum $k$ and ingoing waves in all open channels. Using the R-matrix states, we expand the $\psi_{j}^{-}$in the following way:

$\left(\psi_{j}^{-}\|D\| \psi_{0}\right)=\frac{1}{a} \sum_{k} \frac{\left(\psi_{k}\|D\| \psi_{0}\right)}{E_{k}-E_{0}-\omega} \boldsymbol{w}_{k}^{T} \boldsymbol{R}^{-1} \boldsymbol{F}_{j}^{-}(a)$, where $\left(\psi_{k}\|D\| \psi_{0}\right)$ are the reduced matrix elements between the initial state and the R-matrix basis functions, $\boldsymbol{w}_{k}^{T}$ represent the surface amplitudes of the inner-region solutions on the boundary $r=a$, and $\boldsymbol{R}^{-1}$ is the inverse of the R-matrix (equation 4). Finally, the $\boldsymbol{F}_{j}^{-}(a)$ represents the radial wavefunction of the scattered electron.

\subsection{Calculation}

Unfortunately, there are no existing cross-sections in the literature for the photoionization (PI) of Ge II. In order to predict the accuracy of the current data, both the BP and DARC methods were utilized to calculate the photoionization cross-sections. Within the R-matrix framework, the photoionization of an ion $\mathrm{A}^{N+}$ is closely related to the electron scattering of ion $\mathrm{A}^{(N+1)+}$. Hence, we may use similar target state wavefunctions as input into the photoionization calculation for Ge II that have been developed above for the electron-impact excitation of Ge III.The first calculation incorporates the relativistic atomic orbitals generated for the Ge III residual ion that were calculated using the extended-optimal-level procedure with the GRASP structure code (Dyall et al. 1996). The atomic structure for this model is detailed in Section 2 as the GRASP structure. For the photoionization calculation of atomic ions with $\mathrm{Z}>30$, it is important to consider 

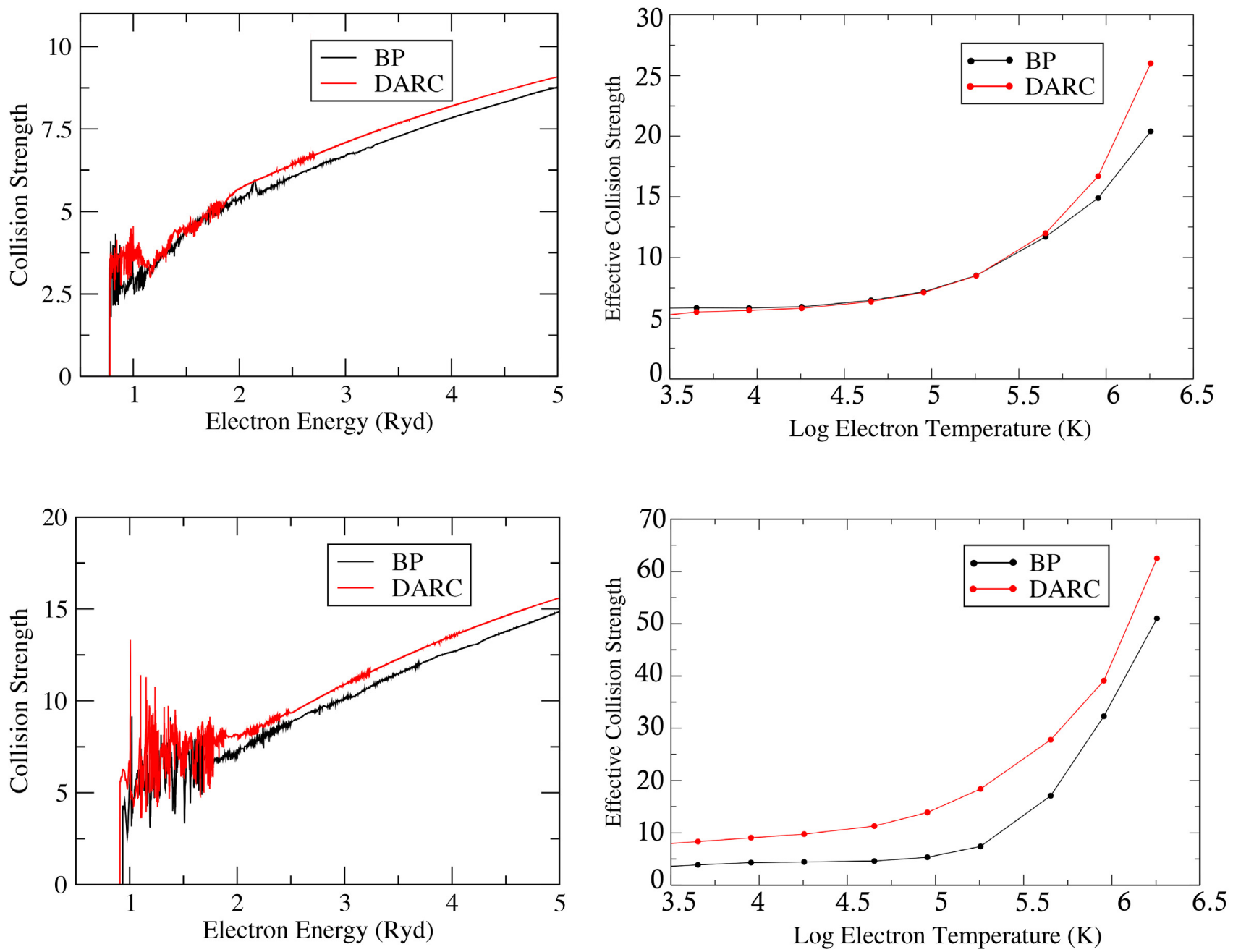

Figure 4. Collision strengths and effective collision strengths for the $3 d^{10} 4 s^{2}{ }^{1} S_{0}-3 d^{10} 4 s 4 p{ }^{1} P_{1}^{o}(1-5)$ and $3 d^{10} 4 s 4 p{ }^{1} P_{1}^{o}-3 d^{10} 4 p^{2}{ }^{1} S_{0}(5-15)$ dipole allowed transitions, respectively, from top to bottom. Presented are both the BP and DARC calculations.

the relativistic and correlation effects in producing accurate models of these systems. The Dirac-Coulomb approach to electron and photon interactions is ideal, and is the approach of the efficient parallel version (Ballance \& Griffin 2006) of the DARC (Norrington \& Grant 1987; Wijesundera et al. 1991). In order to account for the direct 3D photoionization of the ground state, $3 \mathrm{~d}^{10} 4 \mathrm{~s}^{2} 4 \mathrm{p}$, it is important that the model contains the $3 \mathrm{~d}^{9} 4 \mathrm{~s}^{2} 4 \mathrm{p}$ configuration. Our BP model (model 1) adopted in the electron-impact excitation section calculation contains the desired configuration; however, the GRASP model does not. Therefore, a second GRASP structure was generated that also incorporated this configuration (PI model 2). This model comprised of the following nine configurations:

$$
\begin{array}{llc}
3 p^{6} 3 d^{10} 4 s^{2} & 3 p^{6} 3 d^{10} 4 s 5 s & 3 p^{6} 3 d^{10} 4 p^{2} \\
3 p^{6} 3 d^{10} 4 s 4 p & 3 p^{6} 3 d^{10} 4 s 5 p & 3 p^{6} 3 d^{10} 4 s 4 d \\
3 p^{6} 3 d^{9} 4 s^{2} 4 p & 3 p^{6} 3 d^{9} 4 s 5 p^{2} & 3 p^{6} 3 d^{8} 4 s 4 p^{3}
\end{array}
$$

resulting in a 370 fine level structure. The DARC calculation that incorporates this model will be known as DARC370.

Method 2 involves the semirelativistic BP R-matrix approach. This approach has been applied to many atomic ions with atomic number less than 30 for a multitude of atomic systems through the work of the Iron Project (Hummer et al. 1993). The BP model is incorporated into the parallel BP codes, and due to the larger size of the calculation it is sufficient to take 250 levels through the calculation. The results from the PI calculations for Ge II combined with the data from the electron-impact excitation calculations of Ge III are suitable for the incorporation into photoionization modelling codes such as STERNE that numerically simulates the thermal and ionization structure of astrophysical nebulae.

\subsection{Accuracy of GRASP model}

Due to the fact that we are incorporating a new GRASP model into the photoionization calculation, it is important to evaluate the accuracy and uncertainty of this new model against known reliable sources as we have previously done for the BP model. Table 3 presents the energy level in Ryds for the 20 lowest lying states of Ge III for the GRASP model, with comparison made to NIST. For the lowest lying energies produced from the $3 \mathrm{~d}^{10} 4 \mathrm{~s} 4 \mathrm{p}$ configuration, PI model 2 displays good agreement up to an absolute error of $4.90 \mathrm{E}-02$. This model also displays satisfactory agreement with the remaining energy levels available from NIST, particularly the $3 \mathrm{~d}^{10} 4 \mathrm{p}^{2}$ energy levels. 
Table 3. Energy levels (Ryds) for the lowest lying 20 fine-structure levels in Ge III for the GRASP model utilized in the photoionization calculation. Comparisons are made with data available in NIST and the absolute errors for the model when compared to NIST.

\begin{tabular}{lcccc}
\hline Configuration & $J$ & $\begin{array}{c}\text { PI model } 2 \\
\text { Ryds }\end{array}$ & $\begin{array}{c}\text { NIST } \\
\text { Ryds }\end{array}$ & Error \\
\hline $3 \mathrm{~d}^{10} 4 \mathrm{~s}^{2}\left({ }^{1} \mathrm{~S}\right)$ & 0 & $0.00 \mathrm{E}+00$ & $0.00 \mathrm{E}+00$ & $0.00 \mathrm{E}+00$ \\
$3 \mathrm{~d}^{10} 4 \mathrm{~s} 4 \mathrm{p}\left({ }^{3} \mathrm{P}^{\mathrm{o}}\right)$ & 0 & $5.14 \mathrm{E}-01$ & $5.63 \mathrm{E}-01$ & $4.90 \mathrm{E}-02$ \\
$3 \mathrm{~d}^{10} 4 \mathrm{~s} 4 \mathrm{p}\left({ }^{3} \mathrm{P}^{\mathrm{o}}\right)$ & 1 & $5.21 \mathrm{E}-01$ & $5.70 \mathrm{E}-01$ & $4.88 \mathrm{E}-02$ \\
$3 \mathrm{~d}^{10} 4 \mathrm{~s} 4 \mathrm{p}\left({ }^{3} \mathrm{P}^{\mathrm{o}}\right)$ & 2 & $5.36 \mathrm{E}-01$ & $5.85 \mathrm{E}-01$ & $4.85 \mathrm{E}-02$ \\
$3 \mathrm{~d}^{10} 4 \mathrm{~s} 4 \mathrm{p}\left({ }^{1} \mathrm{P}^{\mathrm{o}}\right)$ & 1 & $8.26 \mathrm{E}-01$ & $8.37 \mathrm{E}-01$ & $1.13 \mathrm{E}-02$ \\
$3 \mathrm{~d}^{10} 4 \mathrm{p}^{2}\left({ }^{1} \mathrm{D}\right)$ & 2 & $1.39 \mathrm{E}+00$ & $1.32 \mathrm{E}+00$ & $7.42 \mathrm{E}-02$ \\
$3 \mathrm{~d}^{10} 4 \mathrm{p}^{2}\left({ }^{3} \mathrm{P}\right)$ & 0 & $1.40 \mathrm{E}+00$ & $1.35 \mathrm{E}+00$ & $5.22 \mathrm{E}-02$ \\
$3 \mathrm{~d}^{10} 4 \mathrm{p}^{2}\left({ }^{3} \mathrm{P}\right)$ & 1 & $1.41 \mathrm{E}+00$ & $1.35 \mathrm{E}+00$ & $6.01 \mathrm{E}-02$ \\
$3 \mathrm{~d}^{10} 4 \mathrm{p}^{2}\left({ }^{3} \mathrm{P}\right)$ & 2 & $1.43 \mathrm{E}+00$ & $1.37 \mathrm{E}+00$ & $5.65 \mathrm{E}-02$ \\
$3 \mathrm{~d}^{10} 4 \mathrm{~s} 5 \mathrm{~s}\left({ }^{3} \mathrm{~S}\right)$ & 1 & $1.49 \mathrm{E}+00$ & $1.44 \mathrm{E}+00$ & $4.66 \mathrm{E}-02$ \\
$3 \mathrm{~d}^{10} 4 \mathrm{~s} 5 \mathrm{~s}\left({ }^{1} \mathrm{~S}\right)$ & 0 & $1.61 \mathrm{E}+00$ & $1.49 \mathrm{E}+00$ & $1.19 \mathrm{E}-01$ \\
$3 \mathrm{~d}^{10} 4 \mathrm{~s} 4 \mathrm{~d}\left({ }^{3} \mathrm{D}\right)$ & 1 & $1.85 \mathrm{E}+00$ & $1.48 \mathrm{E}+00$ & $3.71 \mathrm{E}-01$ \\
$3 \mathrm{~d}^{10} 4 \mathrm{~s} 4 \mathrm{~d}\left({ }^{3} \mathrm{D}\right)$ & 2 & $1.85 \mathrm{E}+00$ & $1.48 \mathrm{E}+00$ & $3.71 \mathrm{E}-01$ \\
$3 \mathrm{~d}^{10} 4 \mathrm{~s} 4 \mathrm{~d}\left({ }^{3} \mathrm{D}\right)$ & 3 & $1.85 \mathrm{E}+00$ & $1.49 \mathrm{E}+00$ & $3.62 \mathrm{E}-01$ \\
$3 \mathrm{~d}^{10} 4 \mathrm{p}^{2}\left({ }^{1} \mathrm{~S}\right)$ & 0 & $1.74 \mathrm{E}+00$ & $1.59 \mathrm{E}+00$ & $1.46 \mathrm{E}-01$ \\
$3 \mathrm{~d}^{10} 4 \mathrm{~s} 5 \mathrm{p}\left({ }^{3} \mathrm{P}^{\mathrm{o}}\right)$ & 0 & $1.80 \mathrm{E}+00$ & $1.66 \mathrm{E}+00$ & $1.42 \mathrm{E}-01$ \\
$3 \mathrm{~d}^{10} 4 \mathrm{~s} 5 \mathrm{p}\left({ }^{3} \mathrm{P}^{\mathrm{o}}\right)$ & 1 & $1.80 \mathrm{E}+00$ & $1.66 \mathrm{E}+00$ & $1.44 \mathrm{E}-01$ \\
$3 \mathrm{~d}^{10} 4 \mathrm{~s} 5 \mathrm{p}\left({ }^{3} \mathrm{P}^{\mathrm{o}}\right)$ & 2 & $1.81 \mathrm{E}+00$ & $1.66 \mathrm{E}+00$ & $1.47 \mathrm{E}-01$ \\
$3 \mathrm{~d}^{10} 4 \mathrm{~s} 5 \mathrm{p}\left({ }^{1} \mathrm{P}^{\mathrm{o}}\right)$ & 1 & $1.90 \mathrm{E}+00$ & $1.68 \mathrm{E}+00$ & $2.20 \mathrm{E}-01$ \\
$3 \mathrm{~d}^{10} 4 \mathrm{~s} 4 \mathrm{~d}\left({ }^{1} \mathrm{D}\right)$ & 2 & $1.96 \mathrm{E}+00$ & $1.62 \mathrm{E}+00$ & $3.42 \mathrm{E}-01$ \\
\hline & & & & \\
\hline
\end{tabular}

\subsection{Results}

Both the Dirac-Coulomb and BP methods were used to calculate the photoionization cross-sections. The use of two completely independent structure codes provides reliability and reproducibility of the results. All calculations are shifted to the energy level data recorded in the NIST data base where possible. However, the detail on the NIST data base is lacking, and only a small sample of energies can be shifted for each calculation. The calculations are presented up to 4 Ryds; the double ionization threshold is approximately 3.7 Ryds.

Fig. 5 presents photoionization cross-sections for the $4 \mathrm{~s}^{2} 4 \mathrm{p}^{2} \mathrm{P}_{1 / 2}^{\mathrm{o}}$ ground state (left-hand panel) and the $4 \mathrm{~s}^{2} 4 \mathrm{p}^{2} \mathrm{P}_{3 / 2}^{\mathrm{o}}$ excited state (righthand panel) of Ge II. Very good agreement is evident between the results obtained from the 250-level BP and 370-level DARC evaluations for the positioning of the resonance structures, the magnitude of these features, and the background cross-sections across all photon energies considered. The wide resonance structure seen at around 2.5 Ryd can be accredited to the $3 d^{9} 4 s^{2} 4 p$ configuration that accounts for the direct $3 D$ photoionization of the ground state of Ge II $\left(3 d^{10} 4 s^{2} 4 p\right)$. To further investigate any possible discrepancies, we present in Fig. 6 the excited state photoionization cross-sections from the $4 s^{2} 4 p^{4} \mathrm{P}_{1 / 2}$, $4 s^{2} 4 p{ }^{4} \mathrm{P}_{3 / 2}$, and $4 s^{2} 4 p{ }^{4} \mathrm{P}_{5 / 2}$ metastable states of Ge II. Again good agreement is evident for all photon energies investigated. In the top left plot of Fig. 6, the resonance seen at 1 Ryd comes from the $3 \mathrm{~d}^{10} 4 \mathrm{~s} 5 \mathrm{~s}$ configuration; a second pronounced resonance just after 2.5 Ryd can be attributed to the $3 \mathrm{~d}^{10} 4 \mathrm{~s} 4 \mathrm{~d}$. The conformity between the two data sets gives us confidence in both calculations and indeed in the accuracy of the models incorporated to produce the atomic data.

\section{STELLAR ATMOSPHERE}

The heavy-metal hot subdwarf LS IV $-14^{\circ} 116$ has a surface heliumto-hydrogen ratio of 1:4 by number, and extremely high surface abundances of many trans-iron elements (Naslim et al. 2011; Dorsch et al. 2020). Zinc, gallium, germanium, krypton, strontium, yttrium, zirconium, tin, and lead are overabundant compared with the Sun by factors from 300 (zinc) to 40000 (strontium, yttrium, and zirconium). Being a hot subdwarf, a highly evolved star on the helium main sequence, its high surface temperature and gravity provide ideal conditions for radiative levitation to act on specific ions and produce significant chemical stratification in the stellar atmosphere. While most hot subdwarfs exhibit some signs of chemical stratification, the rare heavy-metal subdwarfs show exceptional overabundances (Jeffery et al. 2015), the precise cause of which is one object of this and other investigations. As prototype in its class, LS IV $-14^{\circ} 116$ is thus an important star for testing atomic data for these species as well as for testing models of chemical diffusion, including radiative levitation, in stellar atmospheres.

The program STERNE (Behara \& Jeffery 2006) is used to compute models for the pressure and temperature structure of the atmosphere of LS IV $-14^{\circ} 116$ in the approximation of local thermodynamic equilibrium (LTE). For hot subdwarfs, LTE remains a good approximation for the structure of the model atmosphere, up to effective temperatures of $\approx 30000 \mathrm{~K}$ (Anderson \& Grigsby 1991) the inclusion of all relevant opacity being more critical. Jeffery, Miszalski \& Snowdon (2021) found fully blanketed LTE models more satisfactory than zero-metal non-LTE models up to effective temperatures of $\approx 40000 \mathrm{~K}$. The approximation is also convenient since STERNE can easily be adapted by us to include new physics, such as additional opacities. For the measurement of abundances using individual spectral lines, departures from LTE can be accommodated in the calculation of the emergent spectrum, as done for LS IV $-14^{\circ} 116$ by Dorsch et al. (2020). Since we are not concerned with measuring abundances in this paper, the LTE approximation implemented here is sufficient to evaluate the impact on the overall opacity of improved structure calculations for individual ions.

We incorporated the DARC370 PI cross-sections for $\mathrm{Ge}^{+}$into the STERNE models. This followed the method previously used for $\mathrm{Sr}^{+}$, $\mathrm{Y}^{2+}$, and $\mathrm{Zr}^{3+}$ by Fernández-Menchero et al. (2020), who also give the model parameters.

For this paper, we used two values for the germanium abundance. The reference value is -0.25 dex times the solar value. The test value is $1000(+3$ dex $)$ times the solar value. We compute three models, one with the reference germanium abundance, one with enhanced germanium contributing only to the new PI opacity (bf), and one with enhanced germanium contributing to both PI $\left(\mathrm{Ge}^{+}\right.$ bf) and photo-excitation (PE, $\mathrm{Ge}^{2+} \mathrm{bb}$ ) opacities. We compare the temperature structures and flux distributions (spectra) of all three models (Figs 7 and 8).

Fig. 7 compares the temperature structure of a model atmosphere with normal and 1800-fold (3.25 dex) enhancement of germanium. The upper left-hand panel shows the temperature structures $(T)$ for both reference and germanium-enhanced models, plotted against monochromatic optical depth $\left(\tau_{4000}\right)$. The lower two panels show the relative temperature difference between the reference and germanium-enhanced models, $\mathrm{Ge}^{+}$PI only on the left and $\mathrm{Ge}^{+} \mathrm{PI}+$ $\mathrm{Ge}^{2}+\mathrm{PE}$ on the right. The upper right-hand panel shows the relative abundances of the first four germanium ions, as well as the region where most photospheric absorption lines are formed.

Fig. 8 compares the emergent fluxes $\left(F_{\lambda}\right.$; $\left.\operatorname{erg} \mathrm{cm}^{-2} \AA^{-1}\right)$ as a function of wavelength $(\lambda ; \AA)$. The top panel shows the overall flux distribution for the reference model. The bottom panel shows the flux differences of the germanium-enhanced models relative to the reference model, with $\mathrm{Ge}^{+} \mathrm{PI}$ only above and $\mathrm{Ge}^{+} \mathrm{PI}+\mathrm{Ge}^{2+}$ PE below.

It is evident that neither $\mathrm{Ge}^{+}$photoionization nor $\mathrm{Ge}^{2+}$ photoexcitation has much effect on the model structure or spectrum of 

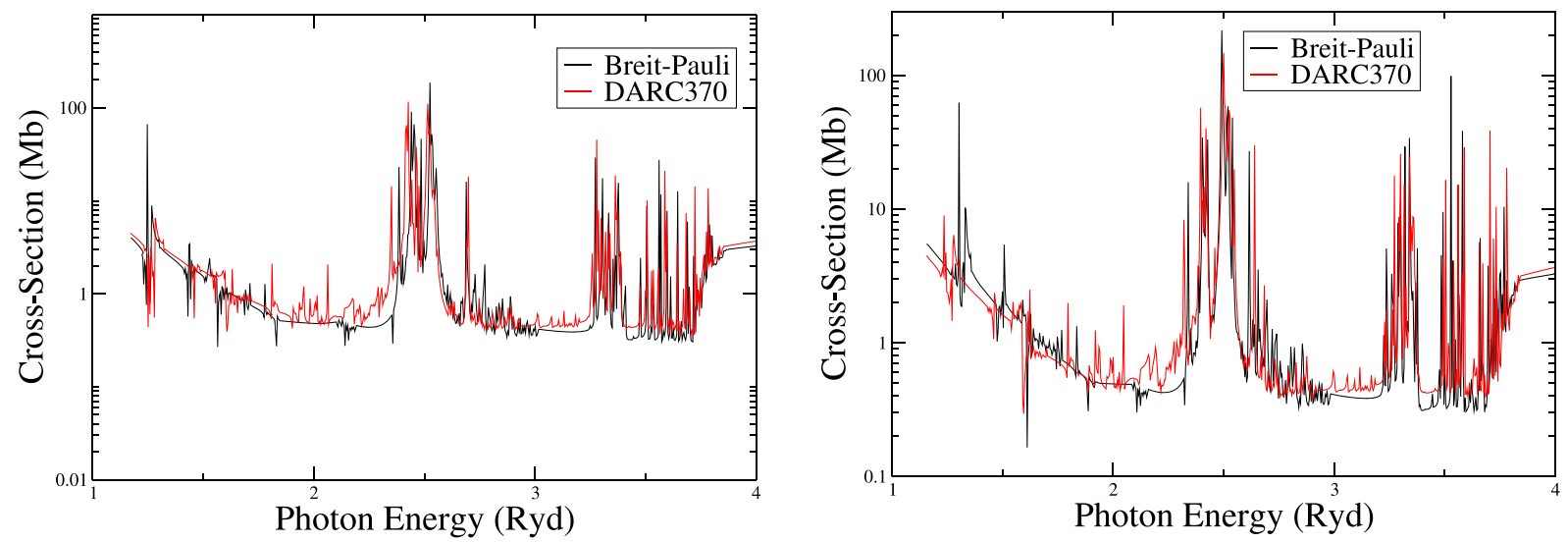

Figure 5. Photoionization of the $4 \mathrm{~s}^{2} 4 \mathrm{p}^{2} \mathrm{P}_{1 / 2}^{\mathrm{o}}$ ground state and $4 \mathrm{~s}^{2} 4 p^{2} \mathrm{P}_{3 / 2}^{\mathrm{o}}$ second state of the $\mathrm{Ge}^{+}$ion, respectively. The cross-sections for the first bound states are illustrated. Theoretical results have been obtained from both the BP and DARC approximations.
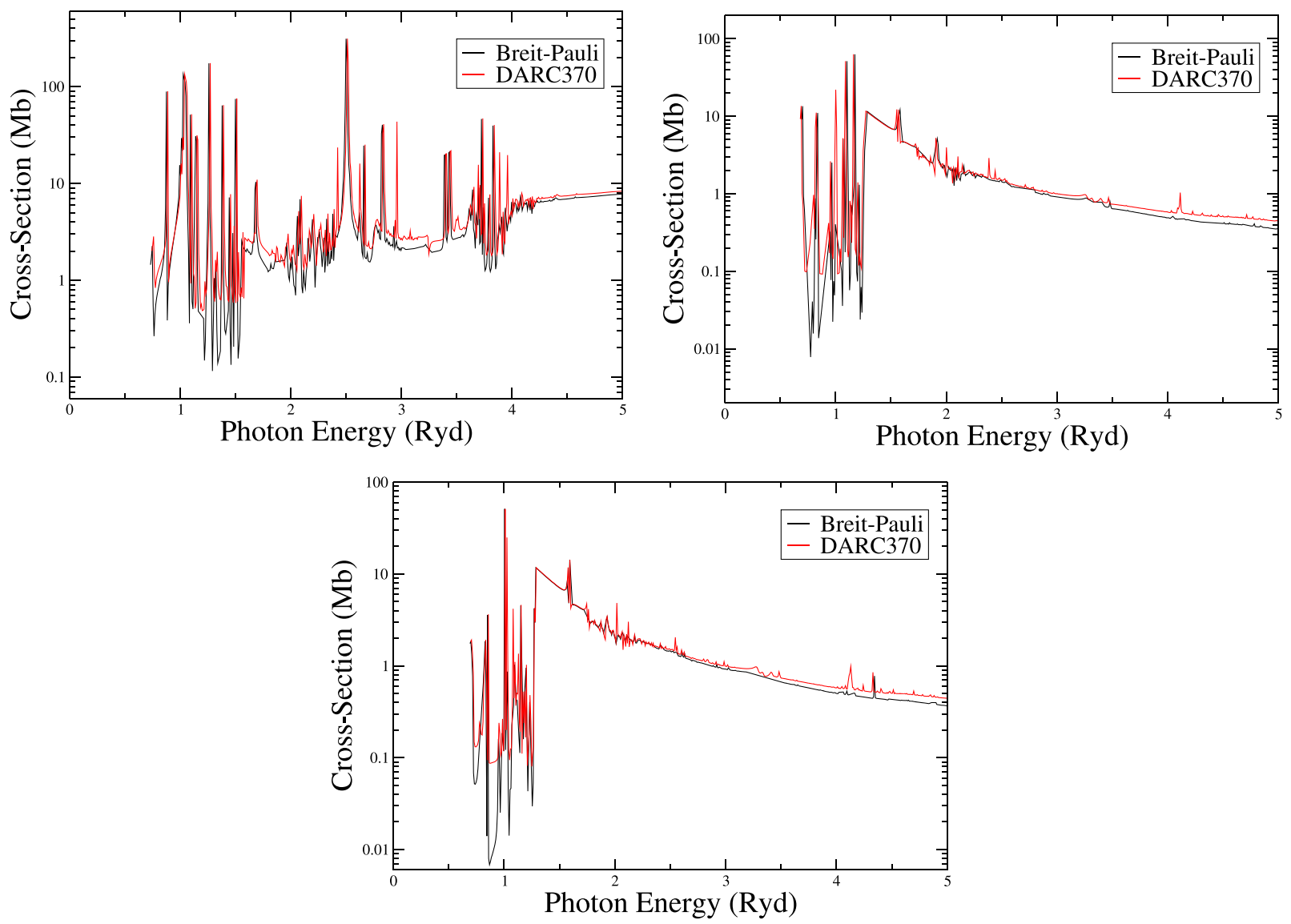

Figure 6. Photoionization of the $4 \mathrm{~s} 4 \mathrm{p}^{2}{ }^{4} \mathrm{P}_{1 / 2}, 4 \mathrm{~s} 4 \mathrm{p}^{2}{ }^{4} \mathrm{P}_{3 / 2}$ and $4 \mathrm{~s} 4 \mathrm{p}^{2}{ }^{4} \mathrm{P}_{5 / 2}$ excited states of the $\mathrm{Ge}^{+}$ion to the ground state of Ge ${ }^{2+}$ ion, respectively. Theoretical results have been obtained from both the $\mathrm{BP}$ and DARC approximations.

LS IV $-14^{\circ} 116$. At best, photoexcitations affect the far-ultraviolet fluxes by 0.01 percent. This may not be unexpected. With an effective temperature $\left(T_{\text {eff }}\right)$ of $34000 \mathrm{~K}$, the fractional ion abundances $\mathrm{Ge}^{+} / \mathrm{Ge}<10^{-5}$ and $\mathrm{Ge}^{2+} / \mathrm{Ge}<10^{-2}$ mean that both contribute little opacity, even when the overall abundance is many times the solar value (Fig. 7).

We can test this in an elementary way by considering a model atmosphere with $T_{\text {eff }}=10000 \mathrm{~K}$. Here, the $\mathrm{Ge}^{+} \rightarrow \mathrm{Ge}^{2+}$ ionization zone straddles the line forming region. $\mathrm{Ge}^{+} \mathrm{PI}$ still has little effect on the models, but $\mathrm{Ge}^{2+} \mathrm{PE}$ produces sufficient opacity to backwarm the lower photosphere by $\approx 0.1$ per cent and increases the far-ultraviolet flux by $\approx 1$ per cent for a 3.25 dex increase in abundance. So we might expect higher ions to contribute more opacity at higher $T_{\text {eff }}$.

While initially disappointing, a null result for LS IV $-14^{\circ} 116$ narrows down the possible causes for the extraordinary surface composition of the heavy-metal subdwarfs. To determine whether and how increasing the germanium abundance impacts the temperature structure and flux distribution of LS IV $-14^{\circ} 116$, we will have to 

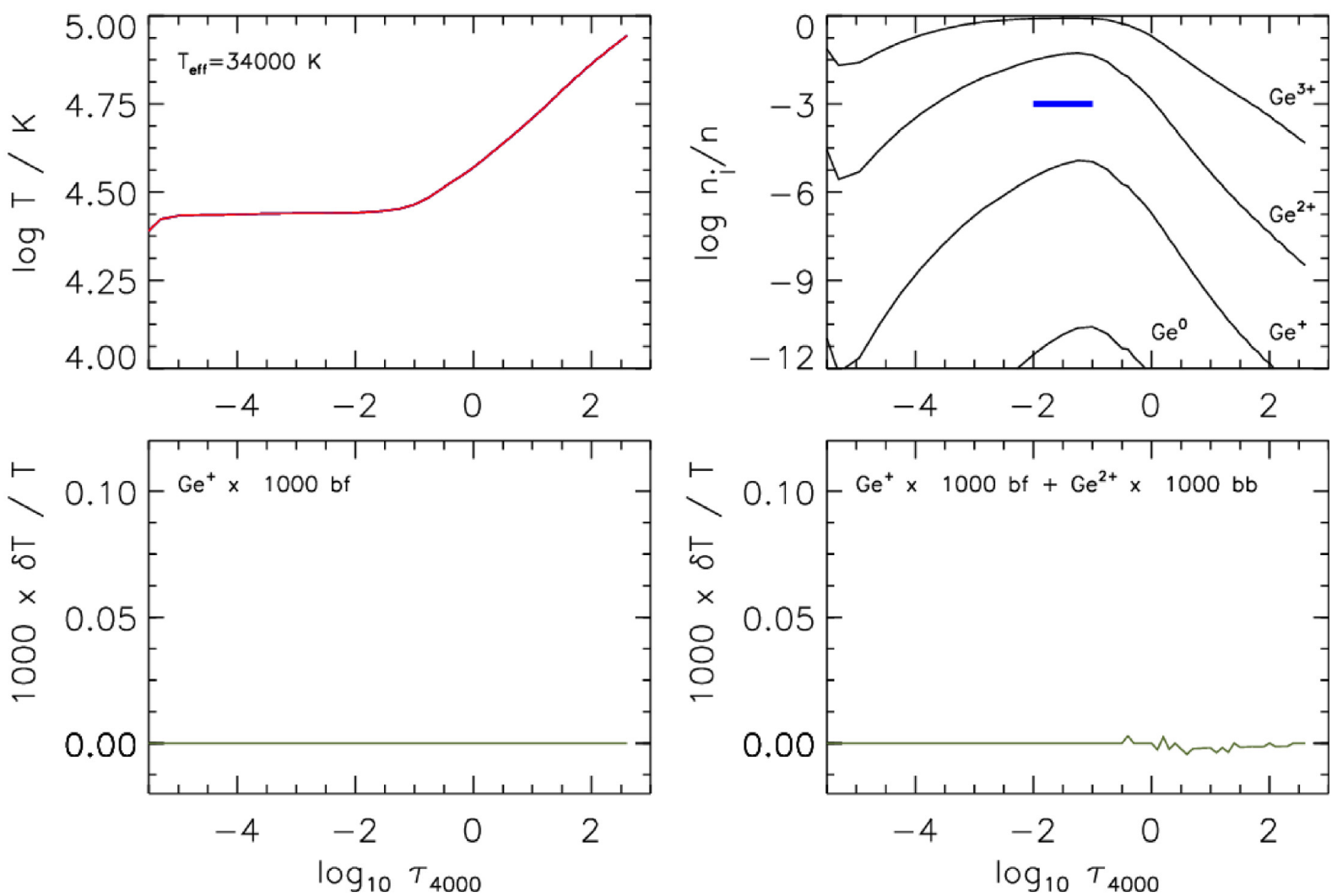

Figure 7. The temperature structure of a model atmosphere with a 1000-fold ( +3 dex) enhancement of germanium is compared with a model having near-solar abundance of the same elements. All models have $T_{\text {eff }}=34000 \mathrm{~K}$ and $\log g / \mathrm{cm} \mathrm{s}^{-2}=5.5$. Other atmosphere parameters are listed in Table A1. All panels are plotted as functions of monochromatic optical depth $\tau_{4000}$. Top left: Temperature structure $T /(K)$ for both the reference model (near-solar abundance of Ge) and the model with Ge abundance increased by $3 \mathrm{dex}$ ). Top right: Ion fractions $n_{\mathrm{i}} / n$ for $\mathrm{Ge}^{0}$ through $\mathrm{Ge}^{2+}$ presented, where $n$ is the total number of germanium atoms. The thick blue bar indicates approximately where absorption lines visible in the spectrum are formed. Bottom left: Relative difference between models with and without the additional contribution of photoionization from $\mathrm{Ge}^{+}$. Bottom right: Relative difference between models with and without the additional contribution of photoionization from $\mathrm{Ge}^{+}$and photoexcitation transitions from $\mathrm{Ge}^{2}+$ (from GRASP).
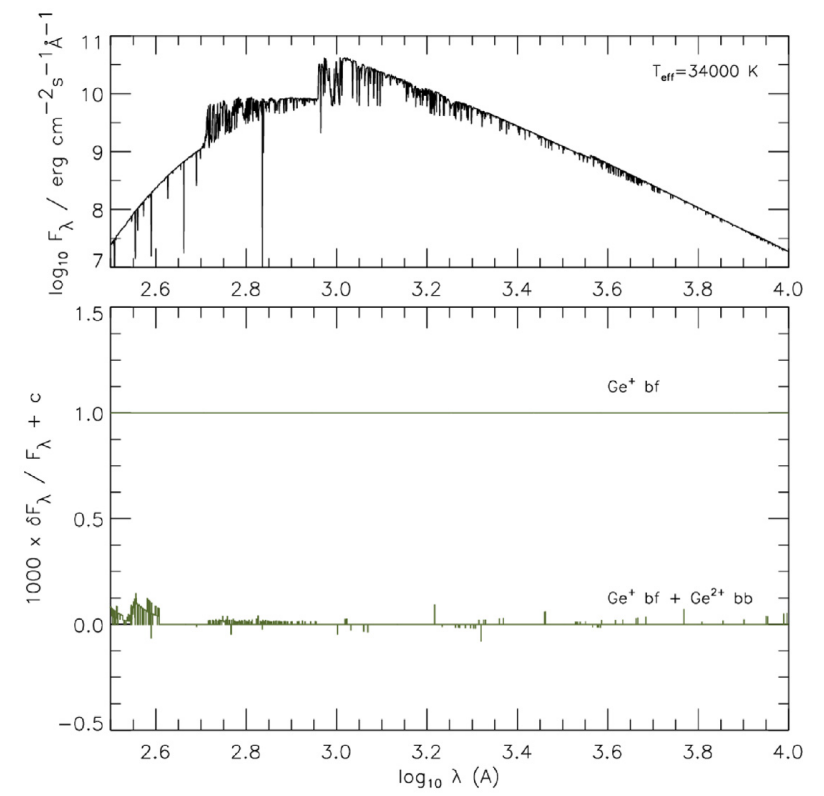

Figure 8. The flux distribution from model atmospheres shown in Fig. 7. All figures are plotted as functions of wavelength $\log \lambda /(\AA)$ with $300 \AA<\lambda<10$ 000 Å. Top: Overall flux distribution for the reference model (black). Bottom: Flux differences of germanium-enhanced models relative to the reference model, with $\mathrm{Ge}^{+} \mathrm{PI}$ only above and $\mathrm{Ge}^{+} \mathrm{PI}+\mathrm{Ge}^{2}+\mathrm{PE}$ below. introduce opacity data for higher ionization stages and $\mathrm{Ge}^{3+}$ in particular. Such data will also be necessary to compute radiative levitation models to establish whether the atmosphere is chemically stratified, and whether the principal agent is photoionization or photoexcitation. Opacity calculations for more highly ionized states will also contribute to internal structure calculations where radiative levitation plays a role, not least in enhancing opacity in layers that contribute to pulsations observed in these stars (Ahmad \& Jeffery 2005; Saio \& Jeffery 2019).

\section{CONCLUSION}

The atomic data reported in this paper represent the largest data set for electron-impact excitation of Ge III currently available in the literature. Two methods were used to create models of the target ion. The GRASP model included 14 configurations in the description of the target ion and utilized the relativistic DARC R-matrix package in the collision calculations. The BP model included 17 configurations in the description of the target ion and the BP codes were used to complete the collision calculation. Collision strengths were evaluated for all transitions, both forbidden and allowed, between all the finestructure levels for incident electron energies up to $5 \mathrm{Ryds}$ for both calculations. We ensured that the Rydberg resonances converging on to the target state thresholds were properly resolved and the convergence of the high partial wave contributions was achieved. 
In order to access the accuracy of the collision strengths, two calculations were completed, a $64 \mathrm{jj}$ level (model 1) and a more substantial $589 \mathrm{jj}$ level (model 2). The corresponding Maxwellianaveraged effective collision strengths were evaluated for a large range of electron temperatures $\left(\log T_{\mathrm{e}}=3.5-6.0 \mathrm{~K}\right)$, exceeding all other previous works. These data sets should provide the necessary quantity and quality of atomic data for modern day modelling of many astrophysical objects.

Due to a lack of existing literature for our target ion, extensive comparisons could not be drawn. However, the $A$-value for the $3 \mathrm{~d}^{10} 4 \mathrm{~s}^{2}{ }^{1} \mathrm{~S}_{0}-3 \mathrm{~d}^{10} 4 \mathrm{~s} 4 \mathrm{p}{ }^{3} \mathrm{P}_{1}^{\mathrm{o}}(108.85 \mathrm{~nm})$ recorded by Morton (2000) was found to be in good agreement with our structure calculation. To ensure accuracy, comparisons were made between the two calculations carried out in this paper. By comparing calculations completed using two independent collision codes, we can be confident in the validity of the results.

The photoionization of Ge II is also presented in this paper. The BP model utilized for the scattering calculation was the model incorporated into the electron-impact excitation of Ge III. However, a new GRASP model was used for the DARC calculations, in order to highlight certain resonance structures in the photoionization crosssections produced. For the BP calculation, 250 levels were retained in the collision calculation. For the DARC370 computations, all levels were carried forward in the calculation. Energies were shifted where possible to the values found in NIST. Photoionization crosssections were calculated up to 4 Ryd, beyond 3.7 Ryds where double ionization takes place.

Using the results from the photoionization of Ge II, we model the theoretical spectrum using the model atmosphere program STERNE. This allowed us to test the validity of our new data and investigate how they contributed to the atmospheres of subdwarf stars. We compared different cases, by using just the PI cross-sections for some models and including the photoexcitation transitions for other models. By including the $\mathrm{Ge}^{+}$and $\mathrm{Ge}^{2+}$ data, we did see an impact on the temperature difference, increased by 0.01 per cent, greater than any of the $\mathrm{Sr}$, Y, or $\mathrm{Zr}$ lines. This is enough of an increase to influence the radiative levitation, meaning that the abundance of these heavy elements in the photospheres of hot dwarf stars could be much higher than the solar abundance.

\section{ACKNOWLEDGEMENTS}

This work is supported by funding from the STFC ST/P000312/1 QUB Astronomy Observation and Theory Consolidated Grant. This work used the Cray XC40 Hazel Hen supercomputer at HLRS Stuttgart. We wish to acknowledge the contributions of R. T. Smyth for their work on the structure and their feedback when compiling this research.

\section{DATA AVAILABILITY}

The effective collision strengths produced here will be made available in an adf04 file via OPEN-ADAS at http://open.adas.co.uk/. The collision strengths if required are available from the authors on request.

\section{REFERENCES}

Ahmad A., Jeffery C. S., 2005, A\&A, 437, L51

Andersen T., Eriksen P., Poulsen O., Ramanujam P. S., 1979, Phys. Rev. A, 20,2621

Anderson L., Grigsby J. A., 1991, in Crivellari L., Hubeny I., Hummer D. G., eds, NATO Advanced Study Institute (ASI) Series C, Vol. 341, Stellar Atmospheres: Beyond Classical Models. Springer, New York, p. 365
Asplund M., Grevesse N., Sauval A. J., Scott P., 2009, ARA\&A, 47, 481

Badnell N. R., 2016, Astrophysics Source Code Library, record ascl:1612.014

Ballance C. P., 2019, DARC, http://connorb.freeshell.org, Accessed: 202108-02

Ballance C. P., Griffin D. C., 2006, J. Phys. B: At. Mol. Opt. Phys., 39, 3617

Behara N., Jeffery S., 2006, Astronomy and Astrophysics, 451, 643

Benredjem D., Mondet G., Calisti A., Gilleron F., Pain J.-C., 2013, in Awwal A. A. S., ed., Proc. SPIE Conf. Ser., Vol. 8602. Adaptive Optics Systems. SPIE, San Francisco, USA, https://hal.archives-ouvertes.fr/hal-00910189

Burgess A., 1974, J. Phys. B: At. Mol. Phys., 7, L364

Burke P., 2011, R-Matrix Theory of Atomic Collisions: Application to Atomic, Molecular and Optical Processes. Springer Series on Atomic, Optical, and Plasma Physics. Springer, Berlin, available at: https://book s.google.co.uk/books?id=B-jQiI8SQY0C

Cashman F. H., Kulkarni V. P., Kisielius R., Ferland G. J., Bogdanovich P., 2017, ApJS, 230, 8

Chi H.-C., Chou H.-S., 2014, J. Phys. B: At. Mol. Opt. Phys., 47, 055002

Cowan J., 2003, Nature, 423, 29

Cunto W., Mendoza C., 1992, Rev. Mex. Astron. Astrofis., 23, 107

Cunto W., Mendoza C., Ochsenbein F., Zeippen C. J., 1993, A\&A, 275, L5

Curtis L. J., 1992, J. Opt. Soc. Am. B, 9, 5

Descouvemont P., Baye D., 2010, Rep. Prog. Phys., 73, 036301

Dirac P. A. M., Fowler R. H., 1928, Proc. R. Soc. A, 117, 610

Dorsch M., Latour M., Heber U., Irrgang A., Charpinet S., Jeffery C. S., 2020, A\&A, 643, A22

Dyall K., Grant I., Johnson C., Parpia F., Plummer E., 1996, Comput. Phys. Commun., 94, 249

Fernández-Menchero L., Jeffery C. S., Ramsbottom C. A., Ballance C. P., 2020, MNRAS, 496, 2558

Fernández-Menchero L., Smyth R. T., Ramsbottom C. A., Ballance C. P., 2019, MNRAS, 483, 2154

Fuhr J. R., Wiese W. L., 2005, in Lide D. R., ed., CRC Handbook of Chemistry and Physics. CRC Press, Boca Raton F

Hibbert A., 1975, Comput. Phys. Commun., 9, 141

Hibbert A., Glass R., Fischer C. F., 1991, Comput. Phys. Commun., 64, 455

Höll R., Kling M., Schroll E., 2007, Ore Geol. Rev., 30, 145

Hummer D. G., Berrington K. A., Eissner W., Pradhan A. K., Saraph H. E., Tully J. A., 1993, A\&A, 279, 298

Jeffery C. S., Miszalski B., Snowdon E., 2021, MNRAS, 501, 623

Jeffery S., Naslim N., Behara N., Hibbert A., 2015, Astron. Geophys., 56, 2.32

Kramida A., Ralchenko Y., Reader J., NIST ASD Team, 2019, NIST Atomic Spectra Database (Version 5.5.6). https://physics.nist.gov/asd, Accessed: 2021-08-02

Kunde V. et al., 1982, ApJ, 263, 443

Lee T.-G. et al., 2020, High Energy Density Phys., 35, 100742

Liu Y., Hutton R., Zou Y., Andersson M., Brage T., 2006, J. Phys. B: At. Mol. Opt. Phys., 39, 3147

Moore C. E., 1971, Nat. Stand. Ref. Data Ser., NSRDS-NBS 35, Vol. II (Reprint of NBS Circ. 467, Vol. II, 1952). Nat. Bur. Stand., Gaithersburg, MD

Morton D. C., 2000, ApJS, 130, 403

Morton D. C., 2003, ApJS, 149, 205

Naslim N., Jeffery C. S., Behara N. T., Hibbert A., 2011, MNRAS, 412, 363

Norrington P. H., Grant I. P., 1987, J. Phys. B: At. Mol. Opt. Phys., 20, 4869

Østensen R. H. et al., 2020, MNRAS, 499, 3738

Saio H., Jeffery C. S., 2019, MNRAS, 482, 758

Smyth R. T., Ramsbottom C. A., Keenan F. P., Ferland G. J., Ballance C. P., 2018, MNRAS, 483, 654

Smyth R., Ballance C., Ramsbottom C., 2019, ApJ, 874, 144

Smyth R., Johnson C., Ennis D., Loch S., Ramsbottom C., Ballance C., 2017, Phys. Rev. A (At. Mol. Opt. Phys.), 96, 042713

Sugar J., Musgrove A., 1993, J. Phys. Chem. Ref. Data, 22, 1213

Summers H. P., 2004, The ADAS User Manual, version 2.6. http://www.ad as.ac.uk, Accessed: 2021-08-02

The Opacity Project Team, 1995, The Opacity Project, Vol. 1. Inst. Phys. Publ., Bristol

Wijesundera W. P., Parpia F. A., Grant I. P., Norrington P. H., 1991, J. Phys. B: At. Mol. Opt. Phys., 24, 1803 

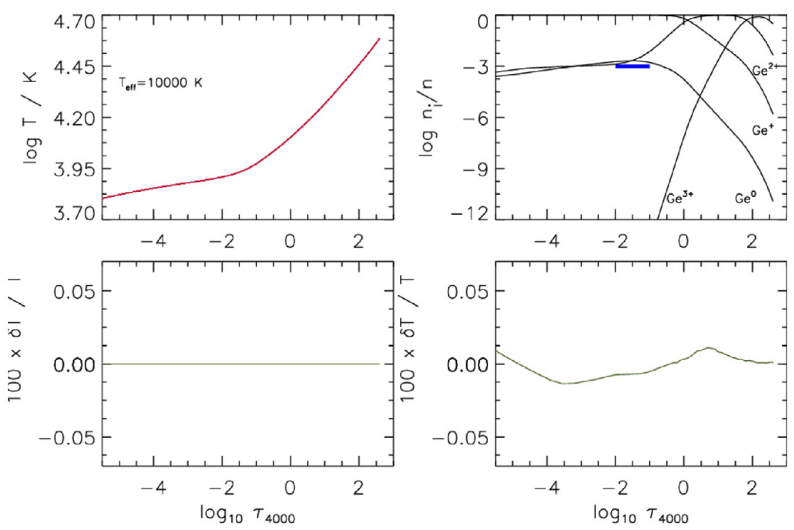

Figure A1. As Fig. 7 for models with $T_{\text {eff }}=10000 \mathrm{~K}$.
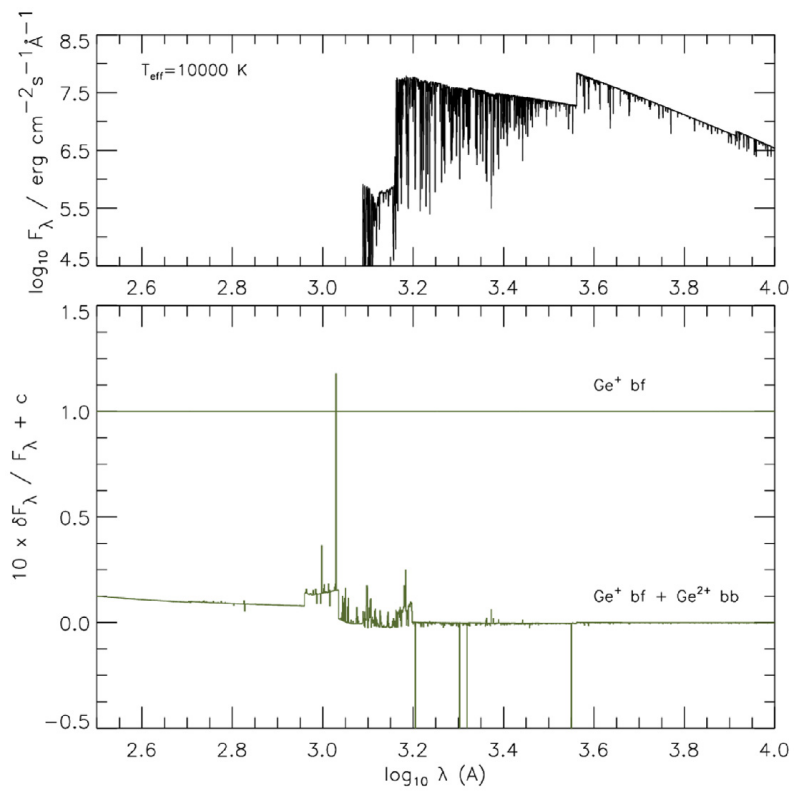

Figure A2. As Fig. 8 for models with $T_{\mathrm{eff}}=10000 \mathrm{~K}$.

\section{APPENDIX A: ADDITIONAL FIGURES AND TABLE}

Figs A1 and A2 compare the internal structure and emergent fluxes for a model atmosphere with an effective temperature $\left(T_{\text {eff }}\right)$ of $10000 \mathrm{~K}$ and all other parameters identical to the test models of Section 5.

Table A1 shows STERNE input parameters for effective temperature $T_{\text {eff }}$, surface gravity $g$, microturbulent velocity $v_{\text {turb }}$, fractional abundances by number $n_{\mathrm{i}}$ of hydrogen, helium, carbon, and nitrogen, and logarithmic abundances of heavier species relative to solar [X].

Table A1. Parameters used to compute the STERNE model atmosphere for LS IV $-14^{\circ} 116$.

\begin{tabular}{lccc}
\hline Parameter & $\begin{array}{c}\text { Adopted } \\
\text { Reference }\end{array}$ & Enhanced & \\
\hline$T_{\text {eff }}(\mathrm{K})$ & 34000 & - & - \\
$\log g\left(\mathrm{~cm} \mathrm{~s}^{-2}\right)$ & 5.5 & - & - \\
$v_{\text {turb }}\left(\mathrm{km} \mathrm{s}^{-1}\right)$ & 5 & - & - \\
$n_{\mathrm{H}} / n$ & 0.64 & - & - \\
$n_{\mathrm{He}} / n$ & 0.32 & - & - \\
$n_{\mathrm{C}} / n$ & 0.014 & - & - \\
$n_{\mathrm{N}} / n$ & 0.014 & - & - \\
{$[\mathrm{O}]$} & -0.8 & - & - \\
{$[\mathrm{Si}]$} & -0.8 & - & - \\
{$[\mathrm{Ca}]$} & -0.25 & - & $Z=17-25^{1}$ \\
{$[\mathrm{Fe}]$} & -0.55 & - & $Z \geq 26^{1}$ \\
{$[\mathrm{Ge}]$} & -0.25 & +3.25 & - \\
\hline $\mathrm{Va}$ & &
\end{tabular}

Value assumed for elements with atomic number $Z$ not specified.

This paper has been typeset from a $\mathrm{T}_{\mathrm{E}} \mathrm{X} / \mathrm{L} \mathrm{T} \mathrm{E} \mathrm{X}$ file prepared by the author. 